\title{
Whither Participation? Evaluating Participatory Policy Processes Using the CGPE Approach: The Case of CAADP in Malawi
}

\author{
Christian Henning, Johannes Hedtrich, Ligane Massamba Sène, \\ and Eva Krampe
}

\section{Introduction}

In response to persisting policy failure in many developing countries, participatory and evidence-based political processes are increasingly promoted as an omnipotent mechanism for guaranteeing unbiased and efficient policies. Scholars who advocate participatory policy processes emphasize two points. First, higher stakeholder participation implies that elected politicians have stronger incentives to represent public interests. Second, stakeholder organizations have an improved understanding of the actions required to promote economic growth and improve the welfare of the poor. Alternatively, some scholars highlight the fact that the development of national economies is a complex process and promote evidence-based policy processes because politicians lack the relevant political knowledge and analytical skills to develop an adequate political strategy for promoting economic growth and reducing poverty. Accordingly, scholars who favor evidenced-based policy processes advocate the active participation of national and international research organizations in policy processes and promote the use of economic modelling for providing adequate political knowledge to responsible political agents. Overall, participatory and evidence-based policy processes are designed to induce more efficient policy decisions. However, in political practice, designing effective and efficient participatory and evidence-based policy processes is challenging. On one

\footnotetext{
C. Henning $(\bowtie) \cdot J$. Hedtrich

Department of Agricultural Economics, University of Kiel, Kiel, Germany

e-mail: chenning@ae.uni-kiel.de
}

\section{L.M. Sène}

African Union, Addis Ababa, Ethiopia

E. Krampe

European Investment Bank, Luxemborug, Luxembourg 
hand, the ability of stakeholder participations to increase the incentives for responsible politicians to implement policies that favor the interest of the general public is questionable. On the other hand, economic modelling is often criticized by political practitioners as a purely academic exercise that fails to provide practical tools for understanding or designing optimal real-life economic processes (Geurts and Joldersma 2001). Accordingly, scholars promote participatory policy analysis that is characterized by an interaction between economic theory and political praxis to combine the 'objective' knowledge derived from economic theories and empirical data with the 'subjective' knowledge of stakeholder organizations as political practitioners (Durning 1993; Joldersma 1997; Geurts and Joldersma 2001). Moreover, inadequate communication between scientific policy analysts and political actors is proposed to be a principal cause of the limited impact of research on policymaking. For example, the 'utilization of knowledge school' emphasizes the fact that policy analysts and policymakers live in two separate communities (Geurts and Joldersma 2001). Hence, to become more efficient, the relationship between scientific experts and policy actors must be redefined. For example, Duke (1974) discusses the role of the interaction between scientific experts and political practitioners within the theoretical perspective of policy learning.

In this context, we suggest the evolutionary Computable General Political Economy Equilibrium Model (eCGPE) as a quantitative approach to modeling and evaluating policy processes. In contrast to standard political economy approaches that focus on political incentive problems and have primarily ignored imperfect political knowledge as a source of inefficient development policies (for example, see Persson and Tabellini 2000), the CGPE approach explicitly allows a quantitative assessment of the impact of both imperfect political incentives and imperfect political knowledge.

While the theoretical CGPE approach has already been introduced in the chapter "Modeling and Evaluation of Political Processes: A New Quantitative Approach" this chapter provides an empirical application of the CGPE approach to the case of the Comprehensive Africa Agriculture Development Program (CAADP) reform in Malawi. CAADP reform in Malawi is a good case in point. First, despite some positive trends, high levels of poverty, poor health, malnutrition and hunger continue to plague Malawi. Second, while it is commonly agreed that these disappointing outcomes are caused in large part by suboptimal public policies, the causes of the continuing failure of the Malawi government to provide optimal public policies remain unknown. Is the Malawi government unwilling to implement the right policies due to biased political incentives or is the government simply unable to implement effective policies due to inadequate political knowledge? For example, by adopting CAADP, the Malawian government, in agreement with the governments of 21 other African countries, committed to a strong role of agriculture in economic development. The pursuit of a $6 \%$ annual growth rate in agriculture via the allocation of at least $10 \%$ of public resources to the agricultural sector is one of the main principles of CAADP. However, although there is a general agreement among African development specialists that any poverty reduction strategy in Africa must consider rural development and incomes, the role of agriculture in African development is controversial (Brzeska et al. 2012). First, the optimal allocation of public 
resources to agricultural and non-agricultural policy programs is a complex task, which depends on the specific framework economic conditions of a country and must be supported by adequate evidence-based research. In particular, the extent to which technical progress in agriculture is more effective than progress in non-agriculture in inducing substantial economic growth and poverty reduction remains unclear. Moreover, the optimal allocation of scarce public budget resources among different policy programs that promote technical progress in the agricultural and non-agricultural sectors remains unknown. Finally, beyond the relevant question of which sectors are the most important engines of growth in the Malawi economy (i.e., agriculture versus non-agriculture or within agriculture, food crops versus export crops), another important question relates to the optimal allocation of public resources across different policy programs (e.g., extension services versus fertilizer subsidies) or infrastructure programs to promote maximal technical progress.

Overall, using the CAADP reform in Malawi as a case study, we demonstrate in this paper that the eCGPE is an adequate model framework that not only enables a political diagnosis (i.e., the identification of existing incentives and knowledge gaps) but also facilitates the development of a political therapy (i.e., the identification of adequate strategies for reducing the identified political performance gaps).

The structure of this chapter is outlined here. In the next section, we explain the manner in which the eCGPE approach is implemented within GAMS and briefly describe how the different eCGPE modules are empirically specified. In particular, we focus on the derivation and empirical estimation of the PIF module and on the econometric estimation of the policy beliefs and political knowledge of different stakeholder organizations. We then describe the principal results of our political diagnosis using the eCGPE model. We also present different simulation analyses that apply the eCGPE to assess different participatory and evidence-based political decisionmaking processes. The chapter concludes by providing an outlook on future work.

\section{Technical Implementation and Empirical Specification of the CGPE model}

\subsection{Technical Implementation in GAMS}

The model is implemented in GAMS as a mixed-complementary problem and solved using PATH. The program is a straightforward extension of the existing recursive dynamic CGE of IFPRI type 2 and is structured as described in Fig. 1.

In its current version, the eCGPE includes four modules: a sequentially dynamic CGE model (CGE), the policy impact function module (PIF), the political belief formation module (PBF) and the political decisionmaking module (PDM). The voter module described in Chapter "Voter Behavior and Government Performance in Malawi: An Application of a Probabilistic Voting Model" has not yet been fully implemented. We leave that task for future work. The sequentially dynamic CGE 


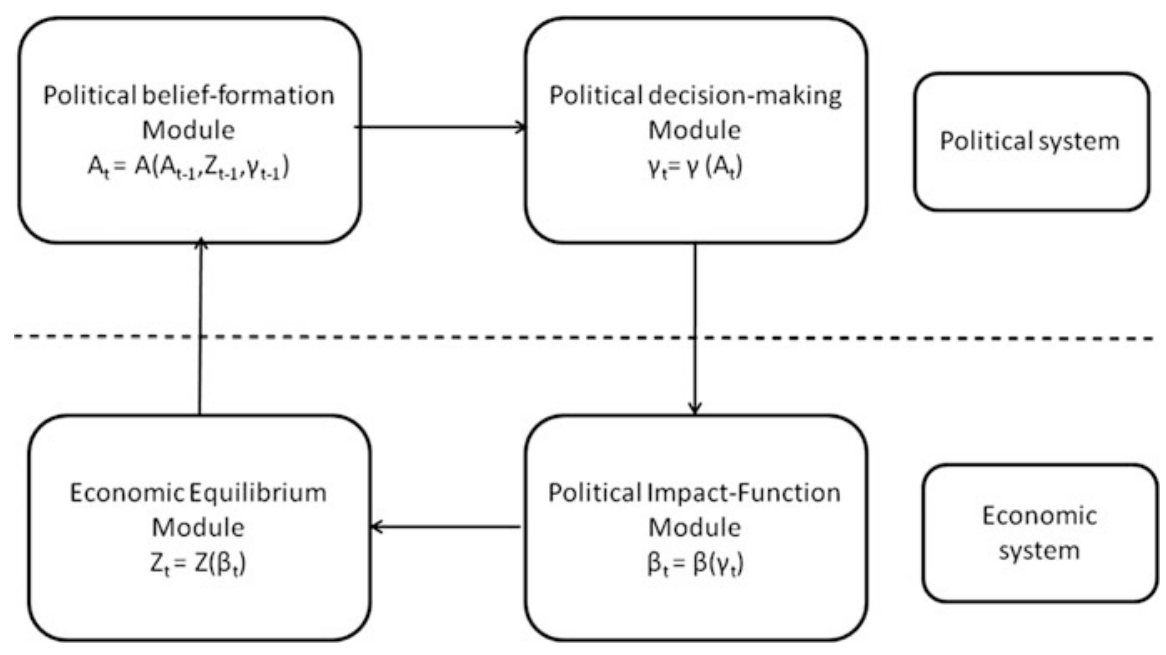

Fig. 1 Model structure of an evolutionary CGPE. Source: Authors

model translates exogenous economic and technological settings into a path of economic outcome variables. For notational convenience, let $\beta$ denote the economic and technological parameters of the CGE. Relevant outcome variables are denoted by the vector $\mathrm{z}$. Thus, it holds: $z=z(\beta)$. Because we are using a quasidynamic CGE, all exogenous and endogenous variables evolve over time, where $Z_{t}$ and $\beta_{t}$ denote the variable values in time period t. Accordingly, we denote by the matrix $Z_{T}=\left[z_{t}\right]$ the development of the relevant outcome variables, where the vector $z_{t}$ corresponds to the sequence of values of the outcome variable $\mathrm{z}$ over the time periods $t=t_{1}, \ldots, t_{T}$. Analogously, the matrix $\beta_{T}$ is the matrix of the development of exogenous CGE parameters over the period $t=t_{1}, \ldots, t_{T}$. A standard CGE application simulates the impact of exogenous policy shocks on the CGE equilibrium path (i.e., on the development path of Z). In particular, policy parameters $(\gamma)$ are incorporated into the CGE model. Technically, this incorporation is accomplished via a policy implementation function, which transforms policy parameters into CGE parameters: $\beta=\beta(\gamma)$. Using the PIFs, a sequence of policy shocks $\left(\gamma_{t}\right)$ is transformed into a sequence of exogenous parameter shocks $\beta_{t}=\operatorname{PIF}\left(\gamma_{t}\right)$, which are translated into a development path of outcome changes $d Z_{T}$ when solving the sequential CGE. A CGPE model extends the standard CGE model by incorporating a policy-decision module (PDM). The PDM determines endogenously the policy choices $\gamma_{t}$ that occur over time. In particular, according to our theoretical CGPE approach the PDM corresponds to a two-stage decision-making model, where at a first stage relevant political actors select a direction, $\Delta \gamma^{\mathrm{M}}$, in which the status-quo policy is shifted and at a second stage political actors vote on a distance $(\lambda)$ the status quo policy is shifted towards the agreed direction. Let $\mathrm{i}=1, \ldots, \mathrm{n}_{\mathrm{I}}$ denote the index of relevant political actors including a subset of legislators and a subset of stakeholders, while $\mathrm{g}=1, \ldots, \mathrm{n}_{\mathrm{g}}$ denotes the index of 
legislators. Each political agent has spatial policy preferences $\mathrm{U}(\gamma)$. Policy preferences are derived from political support maximization.

According to the mean voter decision rule legislative bargaining implies:

$\Delta \gamma^{\mathrm{M}}=\Sigma_{\mathrm{g}} \varphi_{\mathrm{g}} \mathrm{Y}_{\mathrm{g}}$, while the distance results as median, $\lambda^{\text {med }}$ of the individually preferred distances of legislators, $\lambda_{\mathrm{g}}$.

To include lobbying influence prefered policy positions of legislators result as:

$$
\mathrm{Yg}=\Sigma_{\mathrm{j}} \mathrm{M}_{\mathrm{gj}} \mathrm{Y}_{\mathrm{j}}
$$

Accordingly, lobbying implies an extended mean voter rule:

$$
\Delta \gamma^{\mathrm{M}}=\Sigma \mathrm{j} \mathrm{C}_{\mathrm{j}} \mathrm{Y}_{\mathrm{j}}, \mathrm{C}_{\mathrm{j}}=\Sigma_{\mathrm{g}} \varphi_{\mathrm{g}} \mathrm{M}_{\mathrm{gj}}
$$

The final policy choice is gradually implemented for a sufficiently small $d \lambda$ :

$$
\begin{array}{ccc}
\gamma_{t}=\gamma_{0}+t d \lambda \Delta \gamma^{M}, & \text { if } & \lambda^{\text {med }}>(t-1) d \lambda+\gamma_{0} \\
\gamma_{t}=\gamma_{0}+(t-2) d \lambda \Delta \gamma^{M}, & \text { if } & \lambda^{\text {med }}<(t-1) d \lambda+\gamma_{0}
\end{array}
$$

However, we do not assume that politicians have perfect information regarding the political technology (i.e., the transformation of policies into policy impacts); instead, agents are unaware of the true PIF and CGE model.

Hence, we assume that policy choices depend on political beliefs $\left(\tilde{A}_{t}\right)$. Assuming that beliefs are perfectly exogenous implies that initial beliefs perfectly determine all future policy choices. However, as explained above, politicians engage in policy learning processes, i.e. politicans update their beliefs based on observed policy outcomes and policy beliefs communicated by other actors. Belief-up-dating via communicational and reinforcement learning is modeled in the belief updating module (PBD), which is also incorporated in the eCGPE approach. In particular, communication learning is modeled applying the Friedkin model, while reinforcement learning is applied to the individual preferred distance $\lambda_{\mathrm{i}}$ and is based on agents' political support, $\mathrm{S}_{\mathrm{i}}(\mathrm{z})$. All CGPE modules are programmed in GAMS and integrated into a sequentially linked eCGPE model, as described in Chapter "Modeling and Evaluation of Political Processes: A New Quantitative Approach" above.

\subsection{Empirical Calibration of the eCGPE and Data}

Empirical calibration of a eCGPE model includes the calibration of all four modules (i.e., the CGE model, the policy impact function [PIF], the belief formation model $[\mathrm{PBF}]$ and the political decisionmaking model $[\mathrm{PDM}])$. Because the 
empirical calibration of the CGE model is a well-known standard procedure, we only describe the empirical calibration of the other three models, including the required empirical data. A detailed description of the empirical estimation procedures for the Malawi case has already been described in Chapters "Modeling and Evaluation of Political Processes: A New Quantitative Approach" and "A Network Based Approach to Evaluate Participatory Policy Processes: An Application to CAADP in Malawi."

As described in detail in Chapter "A Network Based Approach to Evaluate Participatory Policy Processes: An Application to CAADP in Malawi," the main parameters of the PBF and PDM can be specified based on data collected via a policy network survey. This type of survey is a standard approach in political sociology and empirical policy network studies (Henning 2009; Knoke et al. 1996; Pappi and Henning 1999; Pappi et al. 1995). In the first step of the policy network study, the set of relevant governmental and nongovernmental organizations $(N)$, the set of relevant policy concerns $(z)$ and the set of relevant policy instruments $(\gamma)$, are identified via expert interviews and document analyses.

In the second step of the policy network study, personal interviews will be conducted with all identified relevant organizations. Within the personal interview, policy network relations with other organizations, including political communication, are collected. Based on the stated network relations of all interviewed organizations, the corresponding global networks can be derived directly (Laumann and Knoke 1987; Henning 2009; Knoke et al. 1996; Pappi and Henning 1999; Pappi et al. 1995). Alternatively, an advanced econometric approach can be applied to estimate global network structures based on the stated network relations of the involved agents (Assmann et al. Chapter "The Formation of Elite Communication Networks in Malawi: A Bayesian Econometric by Approach", Snijders 2002). This approach facilitates the identification of the underlying network-generating process and allows an adequate imputation of missing data. Moreover, this approach allows for the identification of determinants of the structure of policy networks and the identification of possible strategies for designing network structures that imply more efficient policy processes. Further, the stated policy preferences of organizations are collected. In the first stage, organizations state their relative interests $(X)$ and their preferred positions $(\widehat{Z})$, with respect to identified policy concerns. In the second stage, organizations state their relative interests $\left(\Theta^{g}\right)$ and preferred positions with respect to identified policies $(\widehat{\gamma})$.

Based on the stated policy positions of all relevant organizations, the underlying macro policies $\left(\gamma^{P}\right)$ can be identified as latent variables by conducting a principal component analysis (see below for details). The stated relative interest in policy concerns is used to specify the Cobb-Douglas parameters of the individual support functions $\left(X^{i}=\left[X_{i k}\right]\right)$. 


\subsection{Estimation of the Policy Impact Function}

The core of a standard CGE application corresponds to a simulation of exogenous shocks. With respect to content, shocks are changes in economic or political framework conditions. Technically, the impact of exogenous shocks is modeled via shifts of exogenous CGE parameters. However, when specific policy shocks are simulated, policies must be incorporated into the CGE model (i.e., shocks must be transformed into changes in CGE parameters). Technically, this transformation is implemented via PIFs. Some policies (e.g., direct and indirect taxes or tariffs) are already directly implemented in the standard CGE model. However, other policies, such as structural adjustment policies, must be translated into CGE parameters. In particular, reducing poverty and promoting overall economic growth is a key factor for achieving the first MDG goal (Diao et al. 2007; Fan and Rosegrant 2008). A range of policy instruments exist that governments can use to promote the required overall economic growth (e.g., technical progress [t.p.] and improving market access by lowering transaction costs). One key factor for sustainable economic growth is t.p. Thus, following Benin et al. (2012), we focus our policy impact analyses on the promotion of t.p. Please note that the PIF approach can be easily extended to include policy impacts on market access and direct transfers to enterprises or households. However, because this chapter aims to demonstrate how a CGPE approach can be applied empirically and to describe the generated results, we restrict the PIF to t.p. When focusing on policy impacts on the promotion of t.p., two questions arise. First, the sectors in which t.p. has the largest impact on the achievement of the envisaged political goals (e.g., poverty reduction or economic growth) remain unknown. Second, the optimal distribution of scarce financial resources across different policy programs for inducing the largest increase in t.p. (e.g., extension services or interest rate subsidies, etc.) must be determined.

With respect to the first question, Fan and Rosegrant (2008) emphasize that many African countries spend too little on promoting agricultural growth compared to non-agricultural growth. Further, with respect to the second question, budget allocations to different agricultural policy programs significantly affect the effectiveness of total budget expenditures. For example, within the Comprehensive Agricultural Development Plan, four different pillars are specified as policy subdomains. Moreover, beyond agricultural growth, overall welfare development is also determined by economic growth in non-agricultural sectors and by the provision of public goods, such as health, education and other social services. Therefore, at the country level, an overall budget allocation must include the allocation of total financial resources for the promotion of economic growth in the agricultural and non-agricultural sectors and the allocation of financial resources for the provision of public goods. For example, Badiane et al. (2011) state that budget allocation to programs that promote future economic growth and the provision of public goods has a significant impact on present and future welfare allocations.

Thus, to identify optimal government budget allocations for promoting economic growth within our CGPE framework, we suggest the following PIF approach. Total government expenditure $\left(B_{t o t}\right)$ results as the sum of total spending 
across policy programs: $B_{t o t}=\sum_{p} \gamma_{p}$. Total government spending determines t.p. realized in the economy, and the effective impact on technical progress $\left(t p_{s}\right)$ that is realized in a specific economic sector $s$ depends on the allocation of governmental spending across policy programs. To capture the importance of different policy programs $p$ to the impact on technological progress that is realized in a specific sector s, the following two-stage policy impact functions $\left(P I F^{s}(\gamma)\right)$ are defined for each sector $(s)$ :

$$
\begin{gathered}
\operatorname{PIF}^{s}(\gamma)=\alpha_{s}^{o} E_{s}\left[B_{s}^{e f f}\right]^{\alpha_{s}} \\
B_{s}^{e f f}=\omega_{s}\left[\sum_{p} \mu_{p s}\left[\gamma_{p}\right]^{-\rho_{s}}\right]^{-1 / \rho_{s}} \\
\frac{s h_{p s}}{s h_{q s}}=\left[\frac{\mu_{p s}}{\mu_{q s}}\right]
\end{gathered}
$$

In the lower stage Eq. (2), budget allocation is transformed into effective budget allocation according to a CES function specification. In the upper stage Eq. (1), an effective budget is translated into t.p. according to a CobbDouglas function (i.e., the marginal impact of additional effective budget spending is diminishing and approximates zero for a sufficiently large effective budget). $\alpha_{s}^{0}$ is a normalization parameter that implies that $E_{s}$ is the maximal rate of t.p. that can be achieved with empirically relevant total budget expenditures for policy programs $\gamma$.

The suggested PIF basically follows the work of Fan and Zhang (2004). However, in contrast to the original approach, the PIF approach is more general and implies a nonlinear relationship between governmental spending and induced technical progress in economic sectors. Moreover, this approach explicitly considers the composition of budget spending for different policy programs. Finally, please note that optimal budget allocation to different agricultural and non-agricultural policy programs varies across different economic sectors (i.e., the same budget allocation translates into different effective budgets that induce different t.p. in different sectors).

In general, an empirical estimation of the PIF function demands a large database of budget expenditures for different policy programs and empirical observations of induced technical progress achieved in different economic sectors. Such a large database is not available for most countries. Accordingly, Diao et al. (2012) estimated an aggregated function that relates the total budget expenditures for agricultural and non-agricultural policy programs to the average t.p. realized in the total agricultural sector.

In this context, we suggest a different approach for estimating detailed and sector-specific PIFs. In particular, we apply a Bayesian estimation procedure that uses interview data from political experts to estimate the parameters of the PIFs. According to our theory, governmental and nongovernmental organizations derive their preferred policy positions $(\widehat{\gamma})$ from the maximization of their political support 
$S(z)$, where support is generated via policy outcomes $\mathrm{z}$. These outcomes are induced by policy choices, giving the underlying political technology $T(z, \gamma)$. As described above, in the CGPE approach, the political technology corresponds to the CGE model and the PIFs, where the CGE model translates the exogenously given t.p. of different economic sectors into the growth rates of different policy concerns z. Let $w_{z}$ denote the vector of the annual growth rates of relevant policy concerns that are induced by a vector of technical progress changes $(\Delta t p)$. Then we can approximate the vector of the annual growth rates of policy concerns implied by exogenously given change in technical progress $(\Delta t p)$ as follows:

$$
w_{z}=\sum_{s} \xi_{z s}^{C G E} \Delta t p+w_{z}^{0}+\xi^{0} \gamma
$$

$w_{z}^{0}$ is the vector of the growth rates that results in the base run, assuming technical progress would not change, while $\xi_{z s}^{C G E}$ denote the CGE elasticities and $\xi^{0}$ denotes the vector of direct policy impacts on outcomes. Both $\xi_{z s}^{C G E}, \xi^{0}$ and $w_{z}^{0}$ can be derived via CGE simulations.

Given this approximation, the support maximization problem of a political agent $i$ results as:

$$
\begin{aligned}
& \operatorname{Max}_{i}\left(1+w_{z}\right) \\
& \text { s.t. : } \\
& w_{z}=\sum_{s} \xi_{z s}^{C G E}(\Delta t p)+w_{z}^{0}+\xi^{0} \gamma \\
& t p=\operatorname{PIF}(\gamma)
\end{aligned}
$$

The solution of the maximization problem results in the optimal policy positions $\left(\widehat{\gamma}_{i}\right)$ and the induced preferred policy outcomes (i.e., the growth rates of policy concerns $\left(\widehat{w}_{z i}\right)$ ) of a political agent i. Accordingly, based on the observed optimal policy positions and the preferred policy outcomes of a set of political agents, the PIF parameters could be estimated econometrically. However, given the large number of parameters, one would need a large set of relevant political agents. Because the set of relevant political agents is rather small (e.g., 36 governmental and nongovernmental organizations in Malawi) a direct estimation of the PIF parameter is impossible because the econometric model is underdetermined (i.e., the number of parameters is larger than the number of observations). To address the specification of underdetermined models, Golan, Judge and Miller suggested the Generalized Maximum Entropy (GME) and Generalized Cross Entropy (GCE) techniques. In a very interesting paper, Heckelei et al. (2008) discussed an alternative Bayesian estimation approach to the GME and GCE techniques. To understand the Bayesian approach for estimating the parameters of an underdetermined model, let $\chi$ denote the vector of the parameters of our PIF functions. Hence, the first order conditions of the political support maximization problem of all relevant political agents correspond to an underdetermined equation system, which we denote $F O C$ $(\chi)$. Further, let $V(\chi)$ denote any prior distribution among the set of PIF parameters $\chi$. Then a solution to the original equation system $F O C(\chi)$ can be obtained from: 


$$
\operatorname{Max}_{\chi} V(\chi) \text { s.t.FOC }(\chi)=0
$$

As long as the prior distribution has a unique maximum within the feasible set of parameters $(F O C(\chi)=0)$, the original parameter estimation problem has a unique solution. Moreover, HMJ demonstrates that the parameter vector $\chi$ that maximizes $V(\chi)$ within the subset of feasible parameter solutions is the mode of the posterior distribution and corresponds to the Highest Posterior Density (HPD) estimate of $\chi$ (Heckelei et al. 2008). Furthermore, we can also add noise to the first order conditions (i.e., $F O C(\chi)+\varepsilon$, where $\varepsilon$ is a vector of error terms). Then assuming that the error terms were independently drawn from $\mathrm{N}(0,1)$, the HPD estimator of $\chi$ results as:

$$
\operatorname{Max}_{\chi, \varepsilon} V(\chi) \prod_{i, p} p_{e}\left(\varepsilon_{i p}\right) \text { s.t.FOC }(\chi)+\varepsilon=0
$$

where $p_{e}($.$) is the standard normal univariate density. Finally, one can also add$ further restrictions on the parameters $\chi$, which correspond to further prior information regarding the parameters $\chi$. This prior information might correspond to theoretical constraints of the parameters $\chi$ or to further empirical information (e.g., expert information regarding minimal or maximal values for specific parameters). Let $\operatorname{RES}(\chi)=0$ denote any further parameter restrictions. Then the HPD estimator of $\chi$ is obtained from:

$$
\begin{aligned}
& \operatorname{Max}_{\chi, \varepsilon} V(\chi) \prod_{i, p} p_{e}\left(\varepsilon_{i p}\right) \\
& \text { s.t. } \\
& \operatorname{FOC}(\chi)+\varepsilon=0 \\
& \operatorname{RES}(\chi)=0
\end{aligned}
$$

Overall, an HPD estimation follows from Eq. (8) using interview data from the policy network survey if a prior probability density function of the model parameters $\chi, V(\chi)$, has been specified and if additional relevant parameter restrictions $R E S(\chi)$ have been specified.

In particular, we assumed that individual parameters are independently normally distributed [e.g., the corresponding prior density function results as: $\operatorname{vec}(\chi) \sim$ $\left.N\left(\chi^{0}, \Sigma\right)\right]$. We derived the prior means $\chi^{0}$ based on existing estimations in the literature (Benin et al. 2012), while the covariance matrix was set equal to the diagonal matrix with the elements $\left[\operatorname{vec}\left(\chi^{0}\right)^{2}\right]$. The specification of the variance of the prior parameters corresponds to the assumption that the coefficient of variance is 1 for all parameters with a non-zero prior mean. If the prior mean was equal to zero, we set the diagonal element to 0.01 .

Given these assumptions regarding the prior density function, the HPD estimator of $\chi$ results as: 


$$
\begin{aligned}
& \operatorname{Min} x\left[\operatorname{vec}(\chi)-\operatorname{vec}\left(\chi^{0}\right)\right]^{\prime} \sum^{-1}\left[\operatorname{vec}(\chi)-\operatorname{vec}\left(\chi^{0}\right)\right]+W_{\varepsilon} \sum_{i, p} \varepsilon_{i p}{ }^{2} \\
& \operatorname{s.t.} \\
& \operatorname{FOC}(\chi)+\varepsilon=0 \\
& \operatorname{RES}(\chi)=0
\end{aligned}
$$

$W_{\varepsilon}$ is the relative weight of the interview data in relation to the expert prior information, which we set exogenously. A high relative weight implies that the estimated PIF parameters are more driven by the interview data from the political agents, while a low weight implies that the final parameter estimations are more driven by the prior information obtained from existing studies. The Bayesian estimation procedure was also implemented in GAMS.

\subsection{Estimation of Individual Policy Beliefs and Political Knowledge}

We understand the policy beliefs of individual political agents as simple mental models for how CAADP policies translate into changes in policy concerns. To capture policy beliefs within the CGPE framework, we estimate for each stakeholder organization the set of PIF parameters and the CGE multiplier that imply that individual political support maximization exactly replicates the policy positions $(\widehat{\gamma}$ and $\widehat{Z}$ ), that an organization stated in the interview of the policy network survey. Basically, we apply the same Bayesian estimation approach described above using only the data and the first order conditions of the political support maximization of one individual stakeholder. Accordingly, we obtain for each individual political agent an estimation $\chi_{i}^{*}$ of the parameters $\chi$. Hence, the estimated parameters $\chi_{i}^{*}$ incorporate the individual policy beliefs of a stakeholder organization. Further, we aggregated estimated individual political technology parameters to common policy beliefs by applying factor and cluster analyses. In particular, we first derived the matrix of first order differentials $A_{i}=\left[a_{i j}\right]=\left[\frac{\partial Z_{i}}{\partial \gamma_{j}}\right]=\sum_{s}\left[\begin{array}{ll}\xi_{z s}^{C G E} & \frac{\partial P I F_{s}}{\partial \gamma_{j}}\end{array}\right]$ as a linear approximation of the estimated individual political technology. Based on the individual matrix elements $\left(a_{i j}\right)$, we first conducted a factor analysis. Based on the factor scores derived for individual stakeholder organizations, we conducted a cluster analysis to identify organizations that hold similar policy beliefs.

Beyond policy beliefs, we are interested in the level of political knowledge of relevant stakeholder organizations (i.e., the degree to which stakeholders' policy beliefs correspond to the true political technology). In the CGPE framework, we measure political knowledge as the level of political support an individual organization $i$ realized based on its stated policy position $\left(\gamma_{i}\right)$ compared to the maximal political support this organization would achieve given the true political technology. If we denote the optimal policy position of an organization as the policy 
position that maximizes its political support given the true political technology by $\widehat{\gamma}_{i}^{o p t}$, it follows for individual knowledge-gaps:

$$
\text { Know }- \text { gap }_{i}=1-\frac{S_{i}\left(\widehat{\gamma}_{i}\right)}{S_{i}\left(\widehat{\gamma}_{i}^{o p t}\right)}
$$

Obviously, individual political knowledge gaps depend on the congruence of stakeholders' policy beliefs and the true political technology. Because it is difficult to identify the true political technology empirically, we will calculate knowledge gaps by simulating different political technologies.

\section{Results}

\subsection{Political Incentives}

Empirically, we derive the political incentives of relevant political agents from their relative interest in different policy concerns, which we collected via personal interviews within the policy network survey. As shown in Fig. 2, the main political interest is the welfare of small-scale farmers $(\mathrm{Z} 1)$, followed by poverty reduction (Z2) and interest in general public services (Z3). In contrast, interest in the welfare of agribusiness (Z4), urban consumer welfare (Z5) and interest in the welfare of agricultural export sectors (Z6) are comparatively low. Interest in environmental

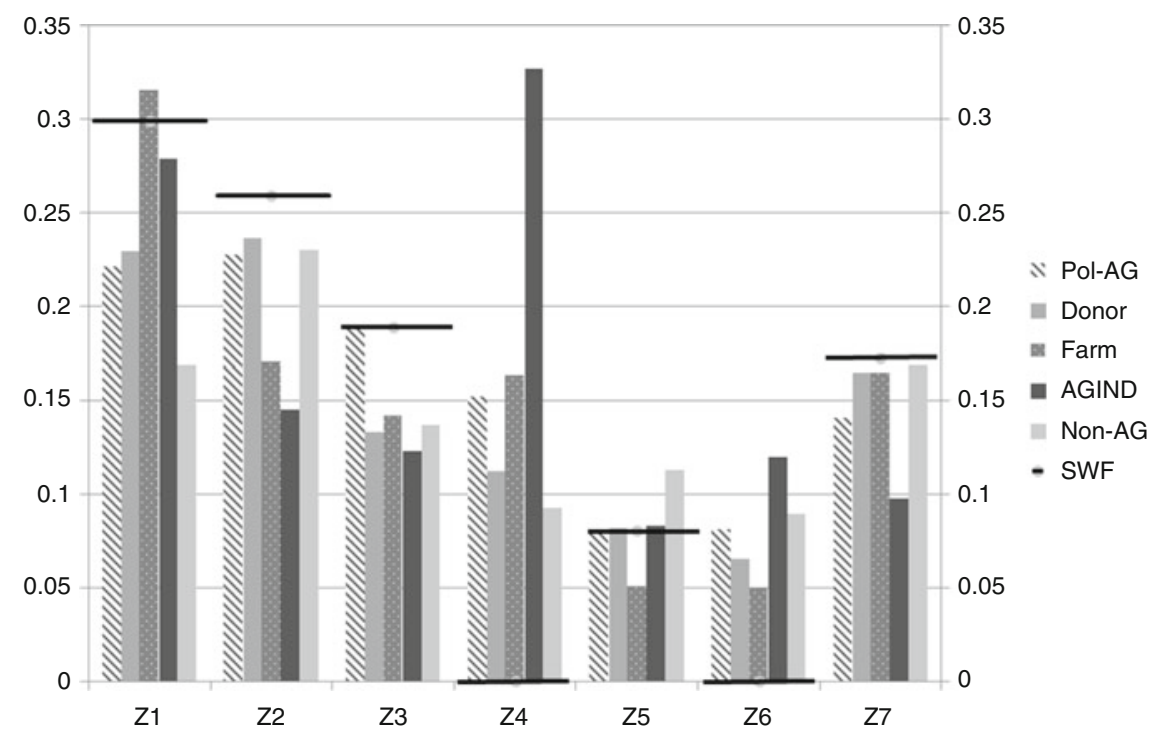

Fig. 2 Interest in policy concerns according to organizational category. Source: Authors 
protection (Z7) occupies a middle ground between the high interest concerns Z1Z3 and the low interest concerns Z4-Z6. Of course, interest group associations that are specialized in the representation of the particular interests of a specific socioeconomic group (e.g., agribusiness and farmer organizations) have extremely high interest in the welfare of their clientele (e.g., farmer associations in Z1 and agribusiness organizations in Z4) (see Fig. 2). In comparison to socioeconomic interest groups, government and international donors and civic society organizations have a relatively higher interest in poverty reduction (Z2) and environmental sustainability (Z7).

Further, we derive a social welfare function based on the collected stakeholder interests. In particular, we set the relative weights of the welfare of particular economic interests (i.e., Z4 and Z6) to zero, while we calculate the relative welfare weights of the remaining policy concerns Z1-Z3, Z5 and Z7 as the average interests of stakeholder organizations. Overall, the following welfare weights result: $X w_{1}=0.299, X w_{2}=0.259, X w_{3}=0.189, X w_{4}=0, X w_{5}=0.08$, $X w_{6}=0, X w_{7}=0.173$.

\subsection{Policy Beliefs and Political Knowledge}

As described above, based on stated policy positions and the achievement of policy goals, we estimated the individual parameters of the PIF and the CGE multipliers that imply that the stated policy positions of relevant governmental and nongovernmental organizations can be replicated from the corresponding political support maximization. Based on the estimated parameters, we calculated the matrix $\left[\frac{d Z}{d \gamma}\right]$ as a linear approximation of the political technology, which we interpret as the policy beliefs of an individual organization. We conducted a factor analysis based on the $7 \times 9=63$ matrix entries for the 36 interviewed organizations and derived the factor scores for the organizations. Based on the computed eigenvalues, we preferred a 7-factor solution.

Moreover, we conducted a cluster analyses of the calculated factor scores of all 36 political organizations, where we preferred a 4-cluster solution. The cluster membership of different organizations is presented in Table 5 in the Appendix, where the identified clusters correspond to similar policy beliefs. To illustrate the estimated policy beliefs, we present a two-dimensional policy belief factor space in Fig. 3. Moreover, we also mapped the factor scores calculated for the original prior parameters of the PIF and the CGE multipliers and for the factor scores derived for the empirically identified political technology (labelled new-prior in Fig. 3). As explained above, the latter parameter was estimated based on the stated policy positions and the targeted policy concern achievements of the interviewed political organizations by applying the Bayesian estimation approach described above.

Figure 3 demonstrates that we can identify a governmental belief cluster (cluster1, colored in green) that includes the most powerful political actors: MoFAS, 


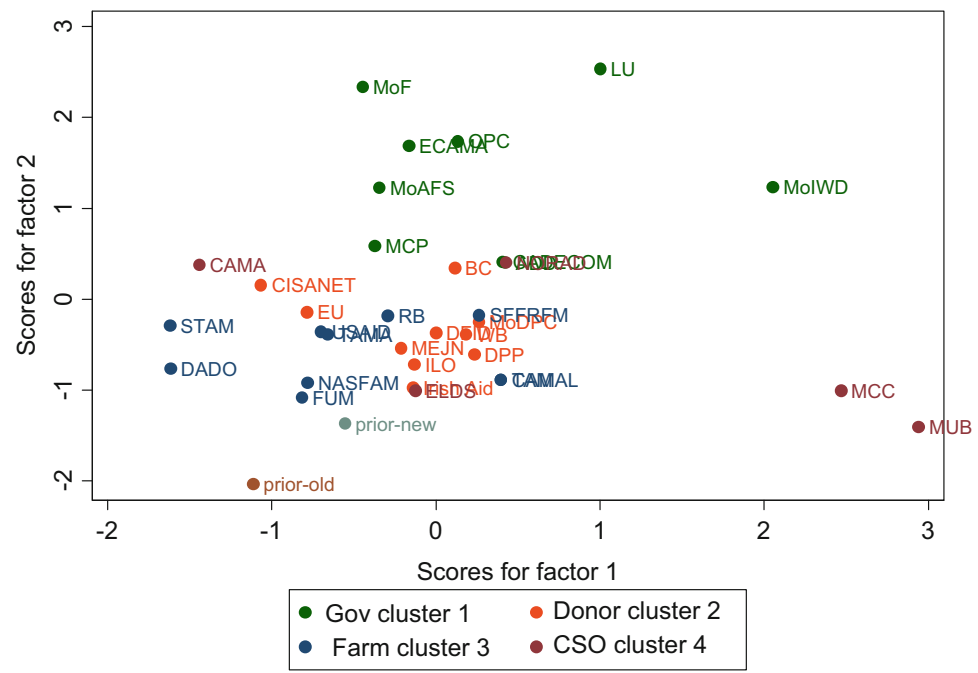

Fig. 3 Factor space of policy beliefs. Source: Authors

MOF and the president, as well as the governmental party MCP, the MOIWD and the governmental agencies LU and ADD (Organization labels are explained in Chapter "A Network Based Approach to Evaluate Participatory Policy Processes: An Application to CAADP in Malawi"). In addition to the governmental belief cluster, we identified a specific agricultural belief cluster (cluster 3, colored in dark gray in Fig. 3) and a civil society belief cluster (cluster 4, colored in blue in Fig. 3); most donor organizations and Bunda College (BC), as the principal national research organization, form a separate donor belief cluster (cluster 2, colored in orange in Fig. 3).

However, not all donor organization appear to hold similar policy beliefs (i.e., USAID is grouped into the farm cluster 3, while the Norwegian donor organization NORAD is grouped in the civil society cluster, e.g. cluster 4, colored red in Fig. 3). Moreover, for comparison, we also mapped the factor scores of the original prior parameters (labelled prior-old in Fig. 3) and the estimated parameters using the stated policy positions of all interviewed organizations (labelled prior-new). Because Fig. 3 only presents the factor scores of the first two factors, while the clustering was conducted using all 7 factors, we will describe the differences between the identified policy beliefs clusters and the prior political technology in more detail in the discussion that follows.

Basically, the impact of CAADP polices on policy outcomes can be separated in three different aspects. First, the relative impact of a specific policy program on the induced technical progress in a specific sector is captured by the CES parameters $\left(\mu_{s p}\right)$. The second aspect corresponds to the efficiency of effective budget expenditure in the generation of t.p. This aspect is captured by the CD parameters $\left(\alpha_{1}^{s}\right)$, which represent the budget elasticity in the production of t.p. (i.e., the percent increase in t.p. change that is induced by a $1 \%$ increase in effective budget allocated 
to promote t.p. in a specific sector s). The third aspect corresponds to the impact of increased t.p. in a specific sector on the change in the achievement of different policy goals. This aspect is captured by the CGE elasticities, where the value of $\xi_{Z S}^{C G E}$ denotes the change in the annual growth rate of a policy concern $\mathrm{z}$ that is induced by a change in the rate of t.p. in the sector s. Hence, the larger a sector in terms of the employment share or the share in GDP, the larger will be c.p. the effect of the CGE elasticities on income growth or poverty reduction, respectively. However, beyond the size of an economic sector, the corresponding CGE elasticities are also determined by interlinkages with other sectors and households. The average estimated parameters are reported for all four belief clusters in Table 5 in the Appendix. Moreover, we also report the original prior parameters and the parameters estimated using the complete policy position data for all of the interviewed stakeholder organizations (labeled new-prior in Table 5). Comparing the estimated parameters of the policy belief clusters to the original prior parameters, we can draw the following conclusions:

1. The political beliefs of all stakeholder organizations differ systematically from the prior parameters derived from economic modeling.

2. Interestingly, although some differences exist across belief clusters, we find a remarkably homogeneous pattern of divergences from the prior technology across all belief clusters. In particular, compared to the prior technology, the policy beliefs of all stakeholders correspond to a significantly higher efficiency of policy programs in promoting technical progress. Specifically, while the prior values of the budget elasticity equal 0.35 for all sectors, the policy beliefs of stakeholders correspond to significantly higher values that range between 0.36 and 0.7 , where stakeholders commonly believe in a high political potential to induce t.p. in the agricultural crop and livestock sectors as well as in the industrial sector. In contrast, for the trading sectors and the public service sector, stakeholder beliefs frequently correspond to slightly lower budget elasticities when compared to the corresponding prior values (see Table 5). Moreover, stakeholders have common beliefs regarding the impact of t.p. that is realized in different sectors on policy concerns. For example, all stakeholder organizations believe that t.p. in both the livestock sector and the public service sector have a significantly higher impact on poverty reduction (Z2), farm incomes (Z1) and the welfare of urban consumers (Z5) when compared to the prior political technology. With respect to the t.p. in the crop, agribusiness and trading sector, stakeholders believe in a comparatively lower impact when compared to the prior technology. For the industry sector, stakeholder beliefs are mixed. For poverty reduction (Z2), a larger impact of t.p. in the industry sector is commonly believed, while for farm income and urban consumer welfare, a comparatively lower impact of the industrial sectors is believed (see Table 5). Finally, with respect to the importance of different policy programs in the generation of t.p. in specific sectors, a remarkably homogenous pattern results for all belief clusters. For example, according to all belief clusters, general fertilizer subsidies $\left(\gamma_{2}\right)$ and non-agricultural policy programs are considered to be much more effective in 
generating t.p. in the agricultural sectors, especially the livestock sector, when compared to the prior technology. Moreover, compared to the prior political technology, investment in general infrastructure $\left(\gamma_{4}\right)$ is much more effective in generating t.p. in the trading and public service sectors, according to the policy beliefs of all stakeholders. Analogously, for generating t.p. in the industrial sectors, stakeholder beliefs commonly indicate a comparatively high efficiency of pillar IV policies (e.g., the promotion of extension services $\left(\gamma_{7}\right)$ and R\&D activities $\left(\gamma_{8}\right)$ (see Table 5 in the Appendix).

3. However, some divergences in policy beliefs also exist between different stakeholder organizations. For example, the civil society cluster (4) believes in contrast to all other stakeholder clusters that investment in infrastructure and the promotion of $R \& D$ activities are especially effective in generating t.p. in the agribusiness sector (see Table 5 in the Appendix).

4. Overall, based on our analyses, we conclude that two worlds exist: the scientific world of economic modelers that corresponds to the prior political technology and the world of stakeholders operating as practical experts in Malawi, which is encapsulated in the observed common policy beliefs. These two worlds are nicely illustrated in Fig. 4, where we plotted the factor scores of stakeholder organizations derived from a factor analysis of their stated policy positions, first assuming that policy positions are derived from policy beliefs (blue dots on the left) and second assuming that policy positions are derived from political support maximization assuming that stakeholders adopt the prior political technology as the true political technology (red dots on the right). Hence, our analyses imply a cleavage between the world of economic modeling and the world of political practice.

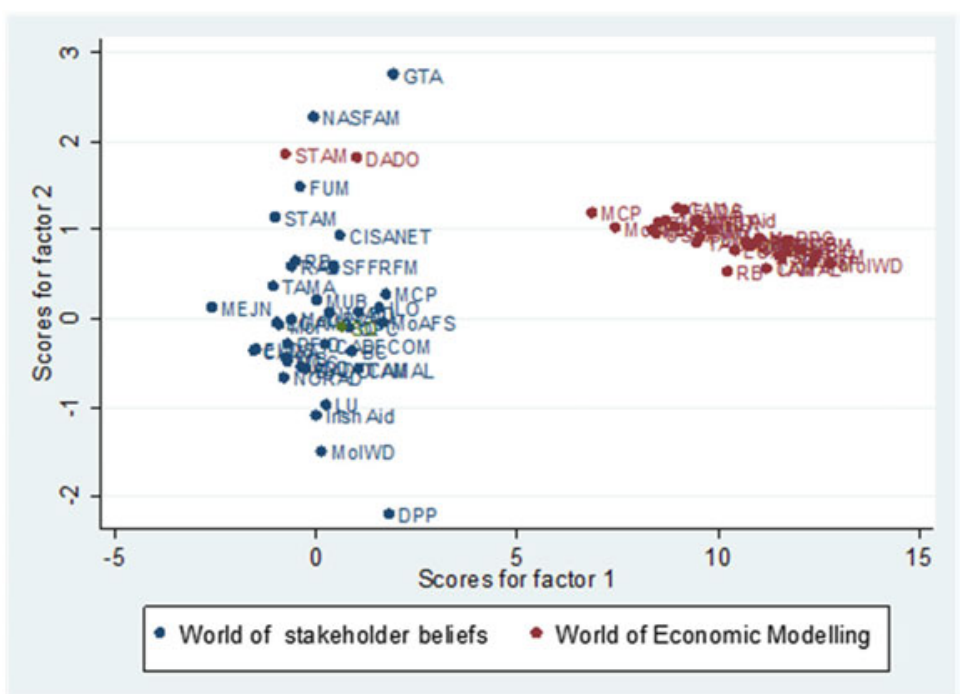

Fig. 4 Preferred CAADP policy positions of Malawi stakeholders in two worlds. Source: Authors 
5. The estimated political technology parameters correspond to a compromise between these two worlds, as shown in Fig. 5. Accordingly, assuming this compromise corresponds to the true political technology, the implementation of more research-based policies can hardly be achieved via increased stakeholder participation, because none of the stakeholder organizations hold policy beliefs that correspond with the scientific world of economic modelling. Interestingly, even international donor organizations fail to hold policy beliefs that closely correspond with the wisdom derived from economic modelling. Given the common assumption in the literature on participatory policy analysis (for example, see Greuts and Joldersma 2001, p. 302) that scientific policy analysts and policymakers exist in two separate communities in reality, we consider this finding to be a remarkable result from our analyses that confirms this common assumption.

A determination of which of the three identified worlds best fits reality is of interest (i.e., is the true political technology better represented by the prior parameters derived from scientific models, by the parameters derived from the policy beliefs of stakeholder organizations as political practitioners or by a compromise between these two worlds, as suggested by arguments of the participatory policy analysis?). The latter possibility corresponds to the PIF parameters estimated using the prior parameter distributions and the complete set of stated policy positions of all involved stakeholder organizations. This question is difficult to answer without further empirical data on specific policy strategies and their impact on realized t.p. and implied poverty reduction and income growth. The answer to this question,

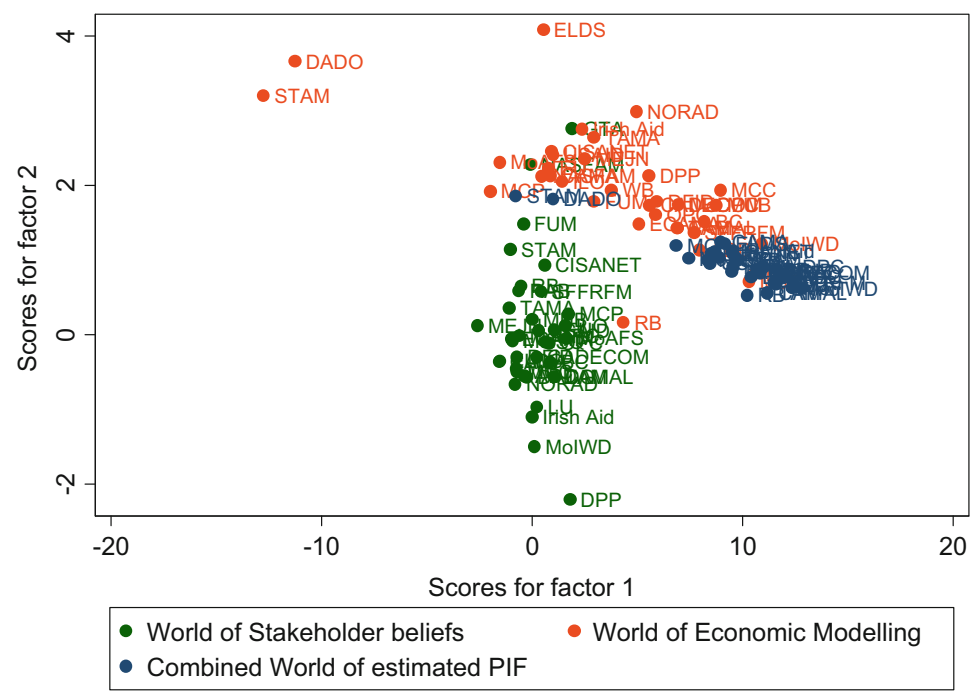

Fig. 5 Preferred CAADP policy positions of Malawi stakeholders in three worlds. Source: Authors 
however, is crucial for evaluating policy processes, particularly the impact of stakeholder participation structures on political performance. Therefore, we will assess political knowledge and incentive gaps by assuming different political technologies corresponding to (a) the prior parameters derived from scientific models, (b) the parameters that result from the Bayesian estimation using prior information and expert data from the policy network survey, as well as the political technologies corresponding to the estimated policy beliefs of the four identified stakeholder belief clusters (labelled a-d for belief clusters 1-4 in the text that follows).

\subsection{Assessing Political Knowledge}

In the CGPE framework, we measure political knowledge as the loss of political support that an individual organization i realizes by comparing the political support achieved under its stated policy position $\left(\gamma_{i}\right)$ to the maximal political support this organization would achieve if it knew the true political technology. Let $\widehat{\gamma}_{i}^{\text {opt }}$ denote the optimal policy position of an organization (i.e., the policy position that maximizes its political support given the true political technology). Then we can calculate the individual political knowledge gaps of each stakeholder organization as defined in Eq. (10) above. In Table 1, we present the average political knowledge gaps calculated for different stakeholder categories for the PIF-Scenarios (a-f) assuming different political technologies. As shown in Table 1, assuming that the true political technology corresponds to the prior-PIF derived from economic modelling, the average political knowledge gaps of stakeholder organizations are high ranging from 30 to $71 \%$ with an average gap amounting 60\%. However, knowledge gaps are significantly smaller for the PIF-scenarios assuming that stakeholder beliefs match true political technology (scenarios a-d in Table 1).

Table 1 Political knowledge gaps of stakeholder organizations, assuming different political technologies

\begin{tabular}{l|l|l|l|l|l|l}
\hline \multicolumn{2}{l}{ Assumed PIF-scenario } & & & & (e) Estimated & \\
\hline Category & (a) Cluster1 & (b) Cluster2 & (c) Cluster3 & (d) Cluster4 & PIF & (F) Prior_PIF \\
\hline AGIND & 18.2 & 17.4 & 16.5 & 16.8 & 23.1 & 30.4 \\
\hline Res & 9.9 & 8.3 & 10.1 & 6.9 & 29.8 & 66.6 \\
\hline Farm & 15.5 & 26.2 & 9.9 & 11.3 & 30.1 & 57.7 \\
\hline Don & 21.3 & 7.6 & 15.2 & 9.7 & 32.7 & 56.5 \\
\hline CSO & 26.1 & 18.2 & 22.1 & 14 & 36.3 & 60.9 \\
\hline Leg & 29.2 & 40.5 & 29.1 & 32 & 38 & 57.2 \\
\hline PUB & 20.2 & 37.9 & 17.9 & 27.4 & 43.4 & 61.6 \\
\hline gov & 18.8 & 27.1 & 23.7 & 22.2 & 46.3 & 70.7 \\
\hline Average & 21.8 & 23.7 & 19.3 & 18.1 & 37.3 & 60.2 \\
\hline
\end{tabular}

Source: Author's own calculations, based on the CGPE model for Malawi 
Accordingly, average political knowledge gaps significantly decrease from 60 to $37 \%$ when assuming that the estimated PIF parameter corresponds to the true political knowledge. However, as shown in Table 1, political knowledge gaps vary also significantly across stakeholder categories. On average, the lowest political knowledge gaps are found for national research organizations (Res), followed by national farmer (Farm) and agribusiness organizations (AGIND). Relatively high political knowledge gaps can be found for the central governmental organizations (Gov), particularly MoFAS and MOF, e.g. for the estimated PIF scenario (e) an average knowledge gap of $46.3 \%$ results for governmental organizations. Only for the PIF-scenario (a) assuming the true political technology corresponds directly to the policy beliefs of the governmental organizations a relatively low gap of $18.8 \%$ is found.

Hence, the political participation of nongovernmental organizations increases the political knowledge used in the political process. In addition, also the political influence of international donor organizations would significantly increase the use of political knowledge. Interestingly, these central results holds true independently of the assumed PIF-scenario with the exception of scenario a.

\section{Political Diagnosis}

\subsection{Assessing Political Performance}

The first indicator of the overall political performance of the political system in Malawi corresponds to the difference between the actual budget allocations decided under the CAADP reform in 2010 and the optimal budget allocations derived from social welfare maximization. To this end, we calculated the optimal budget allocations across CAADP programs and non-agricultural policy programs from social welfare maximization assuming different political technologies. Moreover, we calculated the share of budget expenditures for economic policies in total state budget including additionally expenditures for the provision of public good services. As shown in Table 2, observed budget allocations under the status-quo differ significantly from optimal budget allocations derived for all political technology scenarios. In particular, assuming that the prior PIF corresponds to the true political technology implies a rather low efficiency of economic policy programs in generating t.p.. Accordingly, social welfare maximization implies that the state budget is primarily used to provide public services, such as education, health or social security with an optimal budget share of only $2.5 \%$ for economic policy programs. Although the optimal budget share of total spending for economic policy programs increases significantly, assuming true political technology corresponds to stakeholder beliefs (scenarios cluster 1-4 in Table 2), optimal expenditure shares for economic policy remain low when compared to the status quo. Only following the governmental belief (scenario cluster1) implies a significant higher total state 
Table 2 Budget shares under status-quo policy and optimal policy under different political technology scenarios in \%

\begin{tabular}{|c|c|c|c|c|c|c|c|c|c|c|}
\hline \multirow[b]{2}{*}{ Scenario } & \multicolumn{2}{|c|}{ Pillar I } & \multicolumn{2}{|c|}{ Pillar II } & \multicolumn{2}{|c|}{ Pillar III } & \multicolumn{2}{|c|}{ Pillar IV } & \multirow{2}{*}{$\begin{array}{l}\text { Non-agr } \\
\gamma_{9}\end{array}$} & \multirow[t]{2}{*}{ Total } \\
\hline & $\gamma_{1}$ & $\gamma_{2}$ & $\gamma_{3}$ & $\gamma_{4}$ & $\gamma_{5}$ & $\gamma_{6}$ & $\gamma_{7}$ & $\gamma_{8}$ & & \\
\hline SQ & 20.7 & 6.9 & 2.4 & 4.0 & 2.3 & 3.8 & 1.5 & 1.9 & 56.8 & 30.0 \\
\hline Cluster1 & 1.0 & 3.3 & 0.3 & 26.0 & 1.2 & 3.1 & 1.6 & 28.2 & 35.3 & 45.9 \\
\hline Cluster2 & 1.5 & 7.4 & 0.1 & 36.6 & 1.9 & 6.3 & 1.5 & 13.1 & 31.7 & 17.5 \\
\hline Cluster3 & 0.6 & 3.3 & 0.2 & 34.6 & 1.0 & 2.8 & 1.1 & 27.3 & 29.2 & 21.2 \\
\hline Cluster4 & 2.9 & 7.5 & 1.5 & 8.2 & 2.3 & 5.2 & 2.9 & 1.8 & 67.5 & 19.9 \\
\hline Estimated PIF & 0.5 & 1.7 & 0.0 & 53.1 & 0.6 & 4.7 & 0.5 & 8.4 & 30.4 & 8.9 \\
\hline Prior_PIF & 0.0 & 0.0 & 6.7 & 40.3 & 0.5 & 1.7 & 1.3 & 24.8 & 24.8 & 2.5 \\
\hline
\end{tabular}

Source: Authors

budget share of $45 \%$ for economic policy (see Table 2). Interestingly, CAADP budget shares derived for the different PIF-scenarios (cluster1-cluster4) vary also significantly ranging from only $6 \%$ under the cluster4 scenario to $30 \%$ $(64.7 \% \times 0.459)$ following governmental beliefs (cluster1 in Table 2), while under the status-quo policy Malawi spends $13 \%$ of total state budget for CAADP policies $(0.432 \times 30 \%$, see Table 2$)$. Further, the allocation of budget expenditures across different CAADP pillars differs significantly among political technology scenarios; in particular, spending on subsidy programs under pillar I is drastically reduced under the optimal budget allocation compared to status-quo allocations.

Specifically, under the status-quo policy, a share of over $27 \%$ of total expenditures for economic policy programs is allocated to input subsidies under pillar I ( $\gamma_{1}$ and $\gamma_{2}$ ). The corresponding optimal budget shares range from nearly $0 \%$ for the Prior-PIF scenario to $10.5 \%$ for the PIF-scenario corresponding to the beliefs of the civic society cluster (i.e., cluster 4 ). Vice versa, budget resources allocated to pillar II, particularly resources allocated to improving the general infrastructure $\left(\gamma_{4}\right)$, will be much higher according to optimal budget allocations, where the optimal budget shares of pillar II programs range from $10 \%$ for the civic society cluster beliefs to over $37 \%$ for the donor belief cluster (cluster2). Interestingly, the optimal budget share for pillar II is remarkably higher based on prior and estimated political technology parameters; when compared to the status-quo with a comparatively low budget share of only $6.4 \%$.

To assess the impact of misallocated public budget resources across policy programs, we compare the t.p. induced in different sectors of the Malawi economy under optimal budget allocations to the t.p. induced based on present allocations, as implemented under CAADP by the Malawi government in 2010. In Table 3, the average t.p. rates calculated for different sectors are presented. As demonstrated in Table 3, compared to the status quo scenario, an optimal allocation of public resources across CAADP programs and non-agricultural policy programs implies a significant increase in induced t.p. for most scenarios. Specifically, based on the policy beliefs of stakeholders, the potential t.p. rates that can be maximally induced given optimal budget allocations across policy programs are high for the 
Table 3 Simulated technical progress gaps implied by the CAADP reform in Malawi

\begin{tabular}{l|l|l|l|l|l|l}
\hline Scenario & Crop & Livestock & Agri-business & Industry & Trade & Public service \\
\hline Cluster1 & 14.9 & 16.4 & 7.7 & 15.8 & 2.6 & 3.2 \\
\hline Cluster2 & 10.8 & 7.8 & 3.5 & 3.9 & 1.8 & 2.6 \\
\hline Cluster3 & 6.4 & 7.5 & 4.3 & 6.6 & 1.9 & 3.1 \\
\hline Cluster4 & 3.6 & 7.6 & 3.6 & 5.3 & 1.3 & 2.4 \\
\hline Estimated PIF & 2.5 & 3.1 & 2.9 & 2.7 & 2.7 & 2.6 \\
\hline Prior PIF & 1.3 & 1.3 & 1.5 & 0.9 & 0.9 & 0.9 \\
\hline Status-quo & 2.0 & 2.0 & 2.0 & 2.0 & 2.0 & 2.0 \\
\hline
\end{tabular}

Source: Authors

agricultural and agribusiness sectors, as well as the industry sectors, with t.p. rates ranging between 3.5 and 16.4 (see Table 3). In contrast, following stakeholder beliefs, the potential t.p. rates are comparatively lower for the trading sector and the public service sector, with values ranging between 1.3 and 3.2. In contrast, based on prior PIF-parameters, the optimal t.p. rates are much lower, even lower than under the status quo policy. This follows directly form the fact that for the Prior PIF investments in t.p. are rather inefficient. Accordingly, optimal budget allocations to agricultural and non-agricultural policy programs would be rather low (i.e., only $2.5 \%$ of the total state budget), while a major share of the state budget will be more efficiently used to provide public services.

\subsubsection{Knowledge or Incentive Gaps?}

When using the CGPE framework as a relevant theoretical background, the empirically observed CAADP policies differ from optimal policies (i.e., social welfaremaximizing policies) for two reasons. First, relevant political agents have biased incentives [i.e., $\mathrm{S}(\mathrm{z})$ differs from the social welfare function $\mathrm{SW}(\mathrm{z})$ ]. Second, political agents have biased policy beliefs (i.e., agents' simple mental models approximating the political technology differ from the true political technology). Within the CGPE approach, we can not only estimate the individual policy beliefs and the political incentives of involved stakeholder organizations that determine their stated policy positions, but we can also simulate agents' preferred policy positions derived by assuming different policy beliefs or political incentives. Hence, we can simulate final policy choices by assuming that the policy beliefs of all involved stakeholders correspond perfectly to the true political technology. Comparing the social welfare derived for this scenario to the maximal social welfare derived for optimal policy choices allows us to measure the political incentive gap (i.e., the impact of biased political incentives on political performance). Vice versa, comparing social welfare derived under the assumption that all relevant stakeholder organizations maximize social welfare while maintaining their individual policy beliefs to the corresponding maximal social welfare provides a 
measure of the knowledge gap (i.e., the political performance gap induced by the lack of political knowledge).

Because we are unaware of the true political technology, we calculated the total political performance gaps and the incentive and knowledge gaps that result for the status-quo policy (i.e., the CAADP reform in 2010 in Malawi) for all six political technology scenarios defined above. Figure 6 presents the calculated performance gaps for different political technology scenarios. As demonstrated in Fig. 6, the political performance of the Malawi governmental system crucially depends on the assumption of the true political technology. In the scientific modeling world, political performance is rated low, with a total political performance gap of $72 \%$ (i.e., compared to the optimal budget allocation, the status-quo CAADP policies imply a social welfare that is $72 \%$ lower than the maximum achievable social welfare). Moreover, low political performance results from low political knowledge, where the corresponding knowledge gap also amounts to $72 \%$. The social welfare losses induced by biased incentives amount to only $3.7 \%$ of the maximum social welfare. In contrast, in the world of stakeholder beliefs, political performance would be significantly higher, with total political performance gaps ranging from 7.5 to $19.4 \%$. Moreover, in contrast to the scientific world of economic modeling, in the world of stakeholders' beliefs, political performance gaps result from both incentive and knowledge gaps.

For example, assuming that governmental policy beliefs (cluster 1) match real economic processes in Malawi implies that political performance primarily results

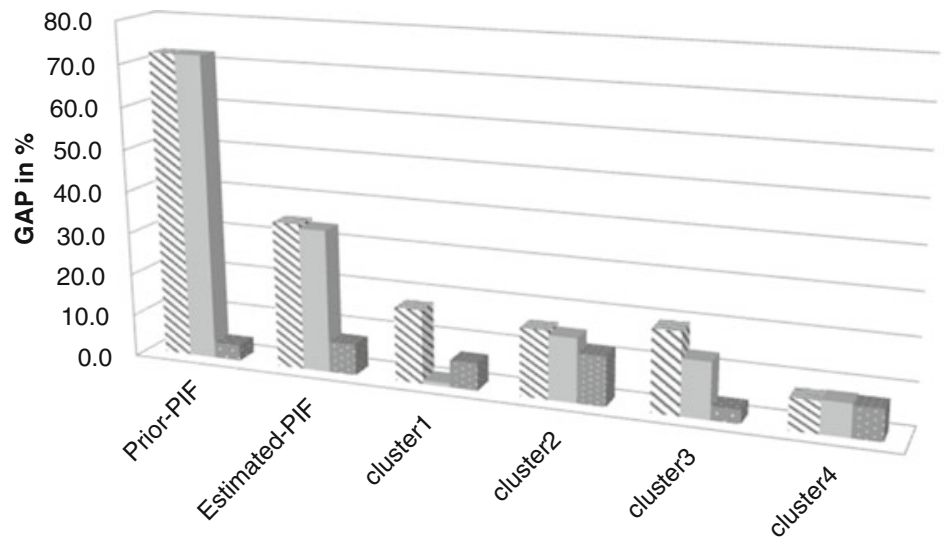

\begin{tabular}{|l|c|c|c|c|c|c|}
\cline { 2 - 7 } \multicolumn{1}{c|}{} & Prior-PIF & Estimated-PIF & cluster1 & cluster2 & cluster3 & cluster4 \\
\hline " Total & 72.3 & 34.7 & 17.5 & 16.0 & 19.4 & 7.5 \\
\hline \#nowledge & 72.3 & 33.8 & 0.9 & 15.1 & 13.2 & 7.7 \\
\hline " Incentives & 3.7 & 7.4 & 6.5 & 11.7 & 3.3 & 7.4 \\
\hline
\end{tabular}

Fig. 6 Total, knowledge and incentive political performance gaps for different political technology scenarios. Source: Authors 
due to biased incentives, while political knowledge gaps are negligible and correspond to only $0.9 \%$ of the maximum social welfare (see Fig. 6).

However, we trust that the Bayesian estimation using both prior information from economic modelling and practical expertise from stakeholder organizations best fits the true political technology. Hence, based on the estimated PIF, we identify significant political performance gaps that correspond to social welfare losses of nearly $35 \%$ compared to an optimal policy decision. The political knowledge gaps are much more important, with corresponding social welfare losses of nearly $34 \%$ in comparison to incentive gaps that correspond to a social welfare loss of only $7.4 \%$ (see Fig. 6).

Moreover, an analysis of the differences in realized growth rates with respect to the achievement of different policy concerns that are induced by political performance gaps is of interest. In Fig. 7, the differences between the growth rates of different policy concerns achieved under the optimal policy and the status-quo policy are presented, assuming that the estimated PIF parameters correspond to the true political technology.

As shown in Fig. 7, performance gaps imply significant differences in realized achievement levels for different policy concerns. In particular, Fig. 7 demonstrates that the status-quo policy implies that the achieved growth rates in agribusiness welfare (Z4), reduction in poverty (Z2) and farm income (Z1) are too high when compared to the optimal achievement levels induced by the optimal policy. In contrast, the increase of total budget expenditures (Z3) for public services and the achieved growth rate in urban consumer welfare are too low when compared to the optimal policy. Please note that these CGPE simulations nicely demonstrate the fact

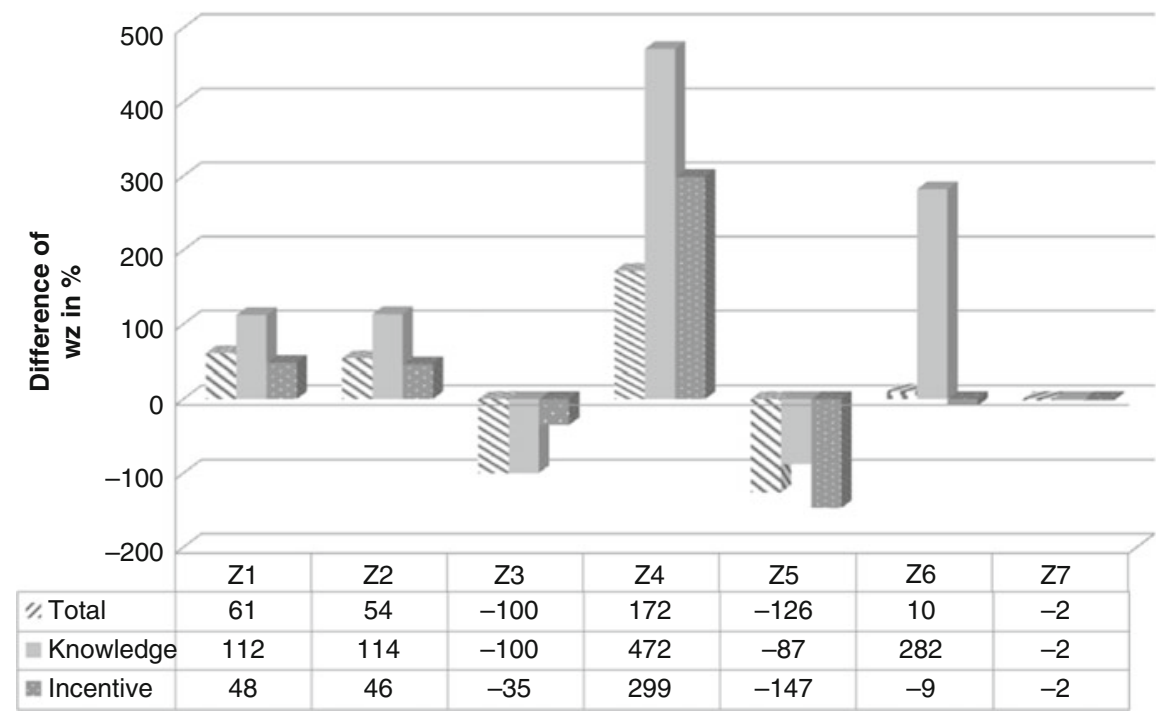

Fig. 7 Total, knowledge and incentive gaps in the achievement of policy goals: Differences in the achievement of policy goals as percentages of the optimal policy. Source: Authors 
that a rapid reduction of poverty does not necessarily correspond to a maximization of social welfare. This follows intuitively from the fact that a rapid poverty reduction might be realized at the expense of a significantly lower income growth or at the expense of a low growth of the public service sector.

\subsection{From Diagnosis to Political Therapy: Simulating Political Performance Gaps with Increased Stakeholder Participation}

To assess the impact of increased stakeholder participation on political performance, we first analyze the changes in final policy decisions and induced political performance that occur when we exogenously assume that specific stakeholder groups have higher political power. In a second step, we analyze the impact of different formal and informal institutional reforms on the political power of different stakeholder groups. Overall, the first simulation experiment reveals changes in participation structures that could improve political performance and the second simulation identifies potential institutional reform strategies for realizing these changes. At the methodological level, the political decisionmaking module of the CGPE approach integrates a modified legislative bargaining model of a Baron/ Ferejohn type with a lobbying model that corresponds to an extended Grossman/ Helpman model. Accordingly, as described in detail in Chapter "Modeling and Evaluation of Political Processes: A New Quantitative Approach," we simulate the impact of different constitutional rules via corresponding changes in the legislative decisionmaking power of relevant political agents (i.e., governmental departments and legislative parties in the parliament). We simulate changes in informal lobbying and communication structures via corresponding changes in political network multipliers (for technical details, see Chapter "A Network Based Approach to Evaluate Participatory Policy Processes: An Application to CAADP in Malawi”).

\subsubsection{Simulation Scenarios}

I. To analyze the impact of stakeholder participation on political performance, we run the following simulation scenarios:
A. Increased political power of international donor organizations (Don).
B. Increased political power of farmer organizations (Farm).
C. Increased political power of civic society organizations (Civic).
D. Increased political power of national research organizations (Res).
E. Increased political power of agribusiness organizations (Agind).

The political power of stakeholder groups in the base run and in the participation scenarios A-E is reported in Table 4. 
Table 4 Simulated political power of stakeholder groups in the CAADP policy domain of Malawi

\begin{tabular}{|c|c|c|c|c|c|c|}
\hline \multirow[b]{2}{*}{ Group } & \multicolumn{6}{|c|}{ Participation scenario } \\
\hline & Base run $(\%)$ & $\mathrm{A}(\%)$ & $\mathrm{B}(\%)$ & $\mathrm{C}(\%)$ & $\mathrm{D}(\%)$ & $\mathrm{E}(\%)$ \\
\hline Gov & 69.6 & 43.5 & 46.4 & 40.9 & 51.5 & 46.4 \\
\hline Leg & 2.3 & 1.5 & 1.6 & 1.4 & 1.7 & 1.6 \\
\hline PUB & 7.7 & 4.8 & 5.1 & 4.5 & 5.7 & 5.1 \\
\hline Don & 6.1 & 41.3 & 4.0 & 3.6 & 4.5 & 4.0 \\
\hline Farm & 6.1 & 3.8 & 37.4 & 3.6 & 4.5 & 4.1 \\
\hline $\mathrm{CSO}$ & 2.6 & 1.6 & 1.7 & 42.7 & 1.9 & 1.7 \\
\hline Res & 1.9 & 1.2 & 1.3 & 1.1 & 27.3 & 1.3 \\
\hline Agind & 3.8 & 2.4 & 2.5 & 2.2 & 2.8 & 35.9 \\
\hline
\end{tabular}

Source: Authors

To analyze the influence of different formal constitutional rules and informal policy network structures on policy decisions and outcomes, we run the CGPE approach under the scenarios described below.

\subsubsection{Benchmark Scenarios}

1. Base run scenario: The base run scenario corresponds to the institutional set-up that implies the best fit between the CAADP decisions predicted by the CGPE and the observed CAADP allocations in 2010. The best fit results assuming that policy decisions are solely determined by the government (i.e., the parliamentary parties have effectively no legislative decision-making power). Within the government we assume the PF-scenario, i.e., the finance ministry has agendasetting power vis-a-vis the president, the MoA and all other involved ministries. With respect to the informal influence of nongovernmental organizations, the weak state scenario delivers the best prediction (i.e., political agents are highly interested in the political support of lobbying groups, and average interest in political support is $50 \%$ ). Moreover, under the weak state scenario, the own control of political agents (i.e., the weight of own political knowledge in comparison to the knowledge of political peer networks) is comparatively low, with an average own control of $50 \%$ assumed under the weak state scenario.

2. Status-quo: Assuming that CAADP budget allocations correspond to the statusquo allocations for all years from 2010 to 2020 .

3. Optimal: Assuming that CAADP budget allocations correspond to the budget allocations across CAADP programs that maximize a social Nash welfare function over the true political technology.

\subsubsection{Simulating Constitutional Reforms}

4. PF: For the PF-scenario we assume that the finance ministry has agenda-setting power vis-a-vis the president, the MoA and all other involved ministries. 
5. PDR: For the principle of departmental responsibility (PDR) scenario, we assume that the legislative organization corresponds to a presidential system, as in the base run scenario, but the government operates under the principle of departmental responsibility, where within the cabinet, the MoA has the total formal legislative decisionmaking power for agricultural policy.

6. PA: For the PA scenario, we assume that the president has the total formal decisionmaking power within the government.

7. Parl: For the party leadership (Parl) scenario, we assume that the legislative organization corresponds to a parliamentary system, where the parliamentary parties exert total legislative decision-making power.

\subsubsection{Simulating the Informal Political Influence of Nongovernmental Organizations}

8. Autarkic (a): Under the autark scenario, we assume that political agents have neither interest in the political support of lobbying groups (i.e., interest in political support is zero) nor interest in the political knowledge of other stakeholders (i.e., own control is one).

9. Strong state (s): Political agents have 50\% lower interest in political support and political knowledge when compared to the base run scenario. Technically, it is assumed that political interest in the political support of lobbying groups is $50 \%$ lower, while the own control of political agents is increased by up to $20 \%$ for the strong state scenario when compared to the corresponding stated values that were empirically collected in the policy network survey.

10. Weak state (w): Own control and interest in political support correspond to the stated values of stakeholder organizations, which are comparatively high, with an average interest in political support of $50 \%$ for all relevant political agents and an average own control of $70 \%$.

For all scenarios except the status-quo and the optimal benchmark scenarios, we assume that political agents engage in reinforcement and communication learning (i.e., based on marginal political support, stakeholders update their policy beliefs as described in Chapter "Modeling and Evaluation of Political Processes: A New Quantitative Approach"). In particular, as a result of the legislative bargaining process, the direction in which the status quo policy is shifted is determined as the mean voter position, where the constitutional decision-making power, which is measured using the generalized Banzhaf index, corresponds to the weight of individual agents. Before the formal political decision is made, agents engage in communication learning, where agents update their preferred direction according to the communicated positions of other agents with whom they communicate. At the stationary point of political communication, each agent's preferred policy direction results as the weighted average of the agents' initial policy positions, where the weight of agent j's initial position in agent i's final position is determined by the communication network (see the theoretical section above for further details). Accordingly, simulating the impact of formal institutions, we assume different formal 
decision-making power of governmental organizations according to the calculated Banzhaf indices. To simulate the impact of political influence of nongovernmental organizations, we assume different interest in political support and different own control values for the weak, strong and autarkic state scenarios, as described above.

\subsection{Whither Participation?}

As demonstrated in Fig. 8 below, it is nearly impossible to identify a vision of participation that could significantly increase political performance. In particular, irrespective of the assumed political technology, neither increased participation of any stakeholder group nor increased participation of international donor organizations implies a significant increase of total political performance when compared to the base run scenario. This result appears surprising at first glance; however, given the fact that the preferred policy positions of stakeholder organizations are primarily determined by policy beliefs, while heterogeneous interests among stakeholders have a comparatively low impact on their preferred policy positions, it follows that any change in participation structures has little impact on policy performance.

The latter conclusion follows directly, because changed participation structures only shift the relative political power of stakeholders and the relative weight of individual stakeholder positions in determining the final policy decision. Thus, because stakeholder positions are empirically similar when compared to the scientific world of economic modelers that is encapsulated in the prior parameters (see Figs. 4 and 5 above), it follows that basically any

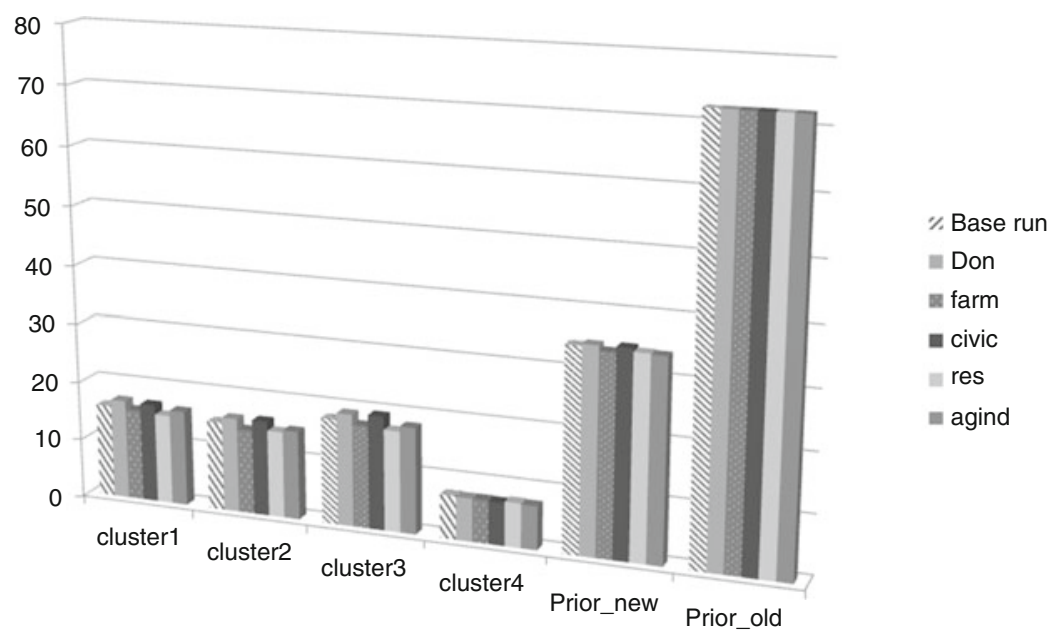

Fig. 8 Total political performance gaps in \% under different participation scenarios. Source: Authors 
participation structure that corresponds to a linear combination of preferred stakeholder positions merely maps into the world of stakeholder beliefs separated from the scientific world of economic modelers. Hence, assuming that the true political technology corresponds to stakeholder beliefs implies a relatively high political performance for any linear combination of policy positions in the world of stakeholder beliefs. Vice versa, assuming that the true political technology corresponds to the prior parameters derived from economic modeling implies that any linear combinations of policy positions in the subspace of the world stakeholder beliefs is rather distant from the subspace defined by the scientific world of economic modeling.

Hence, political performance is low for the base run, but it can barely be improved by any vision of increased stakeholder participation. Basically, this situation drives the results presented in Fig. 9. Hence, if we assume that the estimated PIF parameters correspond to the best representation of the true political technology, one fundamental implication of our simulation analyses is that the interaction between political practice and theoretical modeling implies a particularly successful strategy for improving political performance in Malawi and likely in many other African countries.

In contrast, increased participation of any stakeholder group, such as national farmer associations, civil society organizations, research institutions or international donor organizations, exerts little if any impact on political performance. Basically, this fundamental conclusion does not change if the political performance gaps of constitutional reforms are analyzed. As shown in Fig. 10, the total political performance changes only slightly when assuming different constitutional reforms.

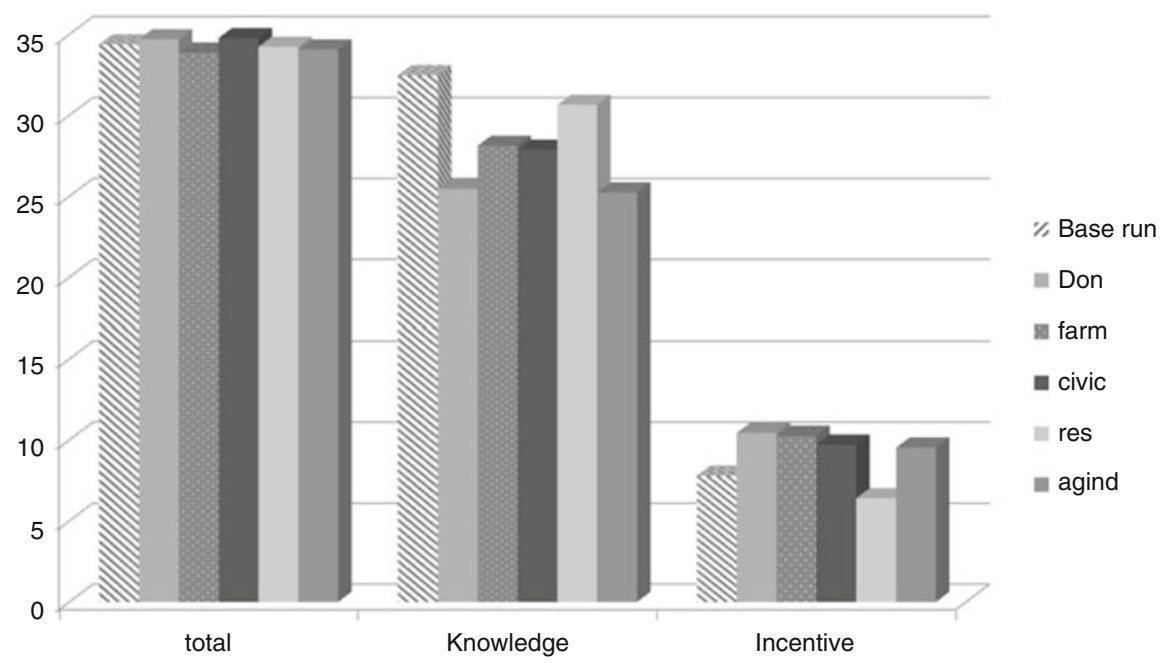

Fig. 9 Total, knowledge and incentive gaps in Malawi (in \% of maximum social welfare). Source: Authors 


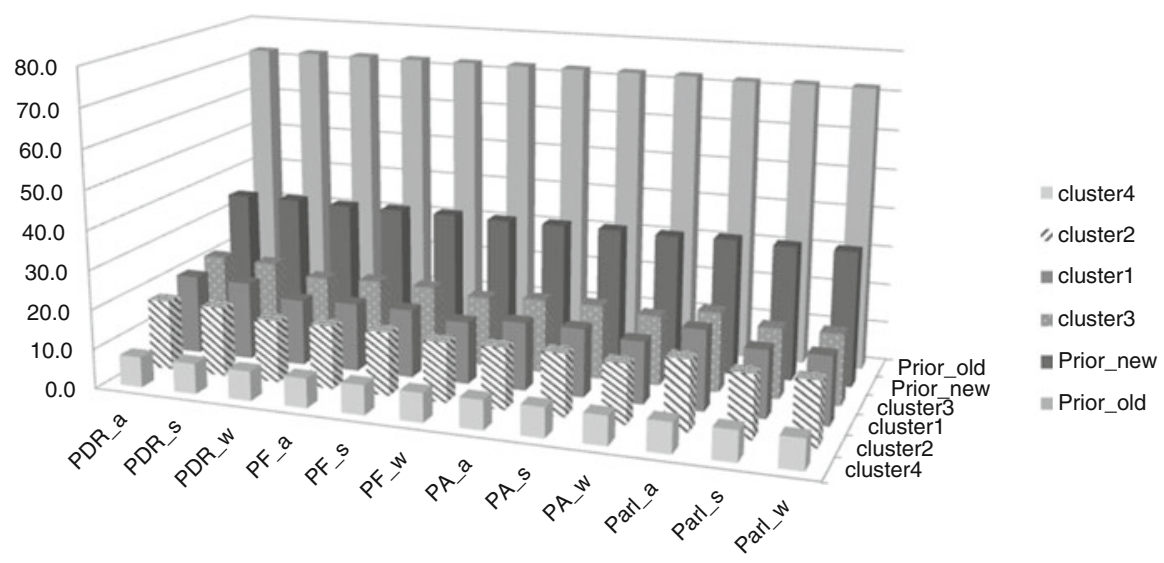

Fig. 10 Total, knowledge and incentive gaps in Malawi (in \% of the maximum social welfare). Source: Authors

\section{Conclusion and Outlook on Future Research}

The common observation that governments persistently fail to implement effective policy and investment strategies that translate into the achievement of development goals in most African countries raises questions about government performance. In particular, low government performance occurs in two forms. First, low government performance occurs as a political incentive gap (i.e., elected politicians lack sufficient incentives to serve public interests and instead serve particular interests or pursue their own interests). Second, low government performance occurs as a political knowledge gap (i.e., the government lacks adequate knowledge and the capacity to identify and implement efficient policies).

In this paper, we develop and apply the CGPE model as a new quantitative approach to analyzing the performance of policy processes with respect to the production of efficient policy choices. In contrast to existing political economy models focusing on biased government incentives the CGPE approach incorporates explicitly the lack of adequate political knowledge as another important source of low government performance. Within the CGPE approach participation of stakeholder organizations is modeled in two ways. First, as classical lobbying influence and second as informational influence within a model of political belief formation. According to our model, the main determinants of the accumulation of political knowledge and the speed of policy learning correspond to policy network structures that reflect the communication and interaction patterns between governmental and nongovernmental organizations.

An empirical application of the CGPE model analyzing the policy processes that underlie the ongoing CAADP reforms in Malawi delivered the following results: 
1. In contrast to standard CGE applications, within the CGPE approach the impact of specific policy programs on induced sectoral t.p. is explicitly captured by policy impact functions (PIFs). Empirically, PIFs are specified in a two-step estimation procedure. At a first stage a prior-PIF is specified bases on available statistical data and existing studies in the literature. In a second step a Bayesian estimation procedure is applied to estimate PIF parameters based on expert data collected from relevant governmental and nongovernmental organizations involved in CAADP reform process in Malawi using PIF- parameters estimated at the first stage as priors. Moreover, applying the Bayesian estimation procedure also allows us to identify individual policy beliefs for each stakeholder organizations as the set of PIF parameters that replicates the stated policy positions and desired goal achievements from individual political support maximization.

2. Our estimation results imply that the estimated policy beliefs of stakeholders differ significantly from the corresponding prior parameters. Hence, we conclude that in the context of the CAADP policies in Malawi, practical policymakers and economic policy analysts exist in two separate worlds. In particular, following the prior PIF-parameters, the political technology of Malawi is characterized by a rather low efficiency of policy programs in promoting technical progress. Accordingly, based on the objective knowledge of scientific modeling, the optimal budget spending under CAADP would be rather low, amounting to only $2.5 \%$ of the total state budget, compared to an observed agricultural budget share of $30 \%$ under the status quo policy in 2010 , while the majority of budget resources would be efficiently used for the provision of public services. Moreover, investments in infrastructure and non-agricultural policy programs are most effective in generating t.p. in both the agricultural and non-agricultural sectors. In contrast, based on estimated stakeholder beliefs, CAADP policies are much more effective in promoting t.p., particularly in the agricultural, agribusiness and industrial sectors, ranging between 3.5 and $16.4 \%$. Accordingly, following stakeholder beliefs, total budget spending under CAADP is significantly higher when compared to prior parameters and ranges between $17.5 \%$ based on donor beliefs and even $45 \%$ based on governmental beliefs. Finally, combing both worlds, i.e. estimated PIF parameters using expert data from stakeholders and scientific knowledge from prior economic studies implies public investments in t.p. that take a middle ground, with an optimal agricultural budget share of nearly $10 \%$ and induced t.p. ranging between 2.5 and $3.1 \%$.

3. Moreover, in the scientific world of economic modeling identified political performance gaps are extremely large, i.e. these amount to nearly $73 \%$ of the maximally achievable social welfare. In contrast, performance gaps are small based on stakeholder beliefs, ranging between 7.5 and $17.5 \%$. Again, in the third world of estimated PIF parameters that combines the scientific world with the world of stakeholder beliefs, achieved political performance occupies a middle ground, with a total gap of 35\%. Interestingly, based on prior and estimated political technology parameters, low political performance results primarily from a lack of political knowledge, while incentive gaps play only a minor role. 
4. Interestingly, changing political influence across governmental and nongovernmental organizations has no impact on political performance, regardless of the assumed political technology scenario. Hence, neither assuming an extremely high political influence of national farm or civic society organizations nor assuming an extremely high political influence of national research or international donor organizations would imply a significant change in political performance. This result appears surprising at first glance, especially because the estimated political knowledge of governmental organizations is low when compared to that of nongovernmental organizations. However, the fact that the estimated policy beliefs of policymakers and stakeholders are comparatively homogenous implies that any combination of preferred stakeholder policy positions still maps into the same world of stakeholder beliefs. Therefore, if this world corresponds to the true political technology, political performance is high under the status-quo and remains high for any participation scenario. Vice versa, if the world of stakeholder beliefs does not correspond to the true political technology, any policy position derived from this world does not intersect with the true political technology; thus, political performance remains low for any participation scenario.

5. Therefore, our analyses of the Malawi case establish the following general and fundamental result: if neither the policy beliefs of policymakers nor the prior parameters correspond to the true political technology, adequate political knowledge does not yet exist in the scientific system or in political praxis and must be created in the political process. Therefore, the only effective political therapy corresponds to the application of adequate tools that facilitate interactive communication and policy learning among stakeholders and economic modelers. However, the most effective organization of this interactive communication in political praxis is an interesting question that we leave for future research.

Finally, the following two limitations of our presented CGPE approach must be considered:

First, in its present version, the CGPE does not yet incorporate the voter module (i.e., political support functions are derived exogenously from interview data). Basically, this setup implies that political support is driven by retrospective and non-policy voting only, while policy-oriented voting is neglected. However, as demonstrated in Chapter "Voter Behavior and Government Performance in Malawi: An Application of a Probabilistic Voting Model," policy-oriented voting is an important determinant of voter behavior. Hence, voters' policy beliefs might effectively restrict politicians' policy choices. This aspect is not fully reflected in the presented CGPE analyses. Thus, incorporating the voter module and deriving political support endogenously from estimated voter behavior might imply that observed political performance is actually more restricted by biased political incentives than implied by the presented CGPE analyses.

Second, by construction, we assume that budget spending for a specific policy program $\left(\gamma_{\mathrm{i}}\right)$ is homogenously effective in promoting t.p. in different subsectors. However, in reality, it appears more realistic that even within specific policy programs (e.g., investments in infrastructure), different subprograms can be 
formulated by focusing on specific subsectors. For example, investing in the infrastructure of specific regions or investing in the railroad system versus the road system might be more or less effective for different subsectors. These differences occur because subsectors might be regionally concentrated or dependent on specific infrastructure systems. Thus, including a third stage in our PIF function that allows for sector-specific subprograms within a specific policy program would imply that preferred policy positions across stakeholder organizations become more heterogeneous; hence, c.p., the induced incentive gaps would also be higher. Again, we leave a more detailed three-stage modeling of PIF functions for future research.

\section{Appendix}

Table 5 Overview of CAADP policy programs

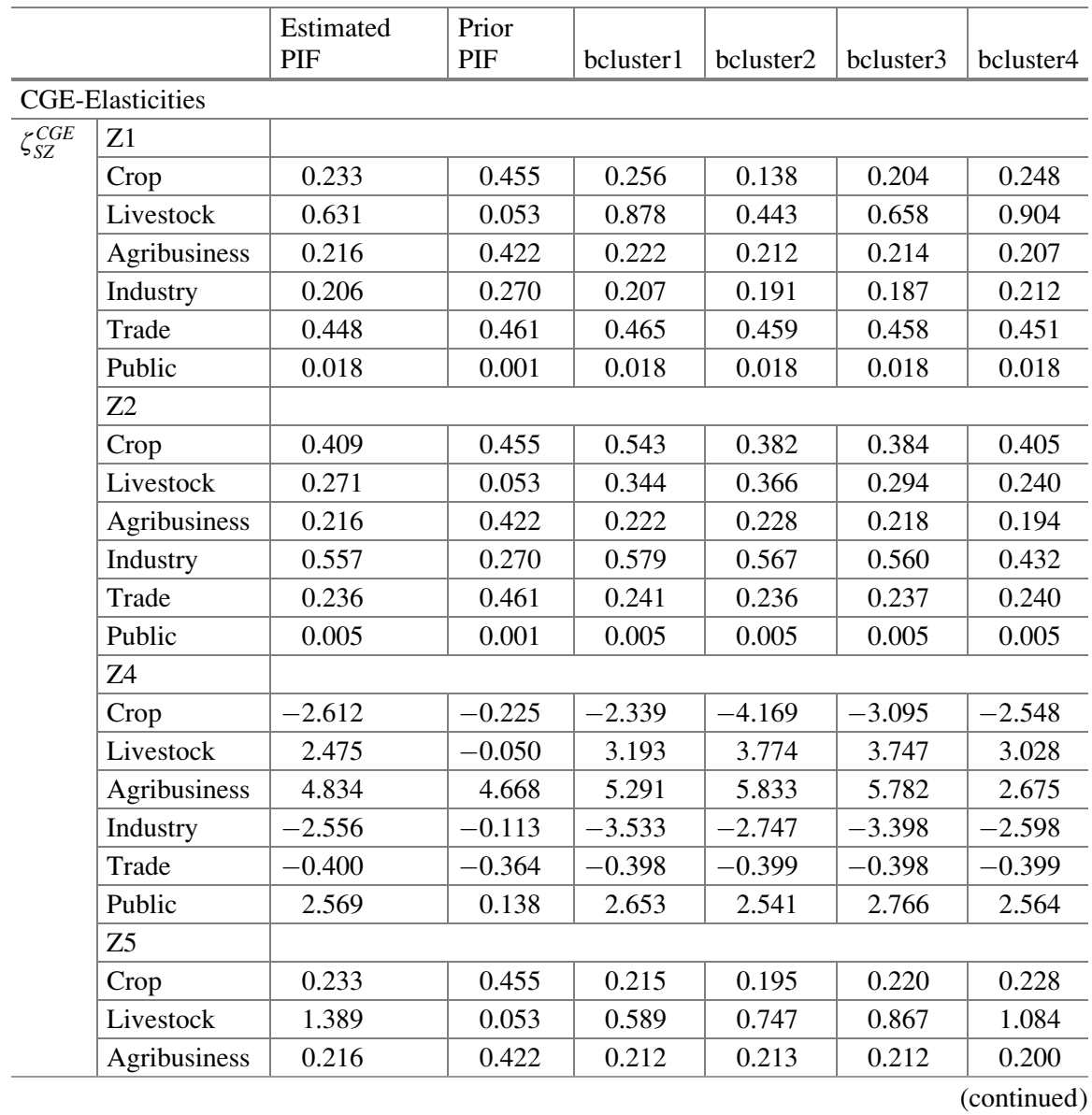


Table 5 (continued)

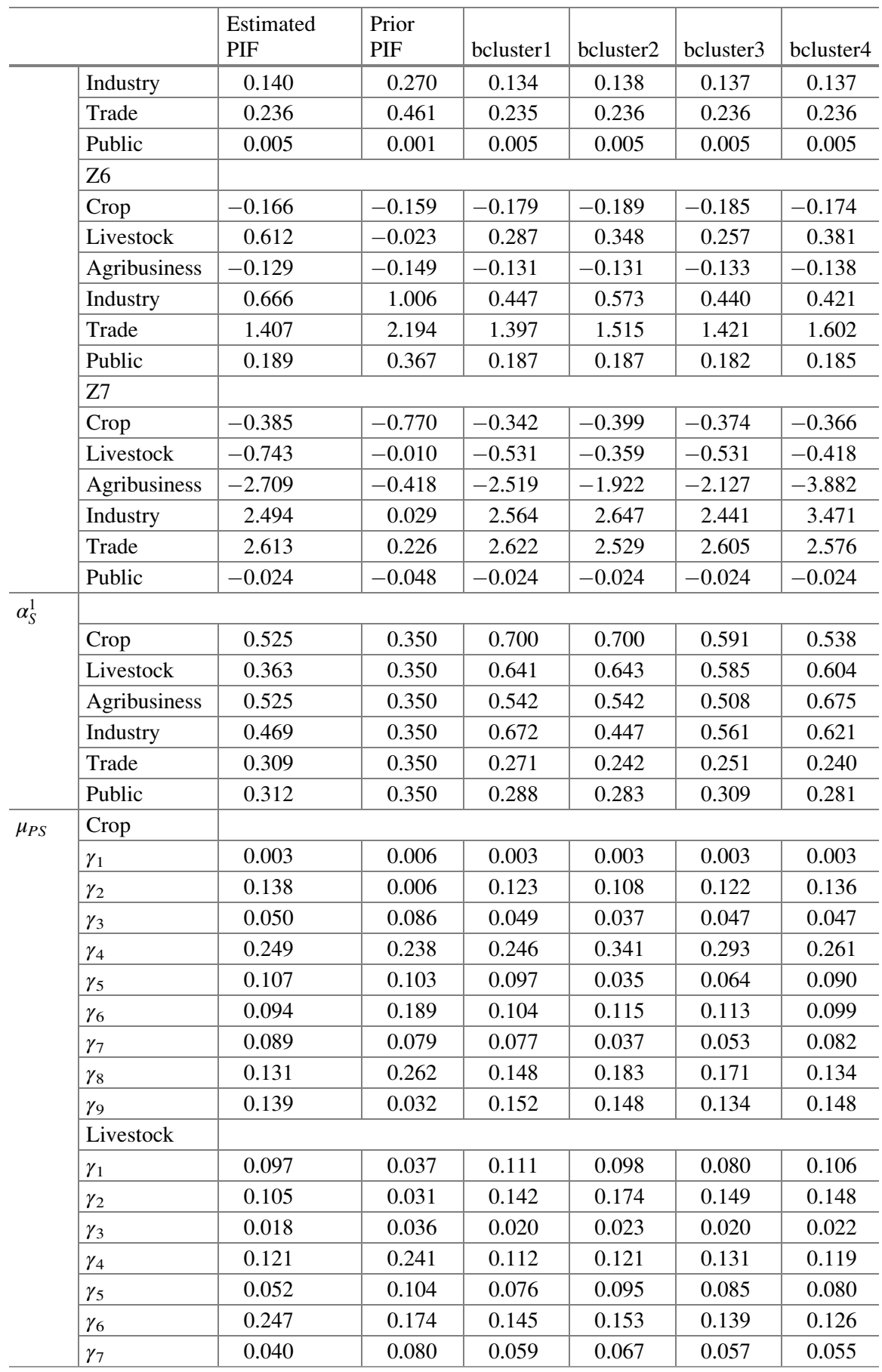


Table 5 (continued)

\begin{tabular}{|c|c|c|c|c|c|c|}
\hline & $\begin{array}{l}\text { Estimated } \\
\text { PIF }\end{array}$ & $\begin{array}{l}\text { Prior } \\
\text { PIF }\end{array}$ & bcluster1 & bcluster2 & bcluster3 & bcluster4 \\
\hline$\gamma_{8}$ & 0.177 & 0.265 & 0.121 & 0.082 & 0.120 & 0.185 \\
\hline$\gamma_{9}$ & 0.144 & 0.032 & 0.214 & 0.186 & 0.219 & 0.160 \\
\hline \multicolumn{7}{|l|}{ Agribusiness } \\
\hline$\gamma_{3}$ & 0.160 & 0.183 & 0.193 & 0.225 & 0.209 & 0.043 \\
\hline$\gamma_{4}$ & 0.286 & 0.256 & 0.292 & 0.300 & 0.315 & 0.346 \\
\hline$\gamma_{7}$ & 0.068 & 0.060 & 0.080 & 0.086 & 0.087 & 0.043 \\
\hline$\gamma_{8}$ & 0.416 & 0.403 & 0.362 & 0.316 & 0.311 & 0.512 \\
\hline$\gamma_{9}$ & 0.070 & 0.098 & 0.072 & 0.072 & 0.078 & 0.066 \\
\hline \multicolumn{7}{|l|}{ Industry } \\
\hline$\gamma_{3}$ & 0.051 & 0.103 & 0.052 & 0.056 & 0.049 & 0.071 \\
\hline$\gamma_{4}$ & 0.297 & 0.343 & 0.261 & 0.300 & 0.302 & 0.244 \\
\hline$\gamma_{7}$ & 0.049 & 0.023 & 0.048 & 0.054 & 0.048 & 0.066 \\
\hline$\gamma_{8}$ & 0.359 & 0.075 & 0.365 & 0.306 & 0.369 & 0.309 \\
\hline$\gamma_{9}$ & 0.243 & 0.457 & 0.274 & 0.283 & 0.231 & 0.310 \\
\hline \multicolumn{7}{|l|}{ Trade } \\
\hline$\gamma_{3}$ & 0.051 & 0.103 & 0.052 & 0.053 & 0.052 & 0.053 \\
\hline$\gamma_{4}$ & 0.671 & 0.343 & 0.668 & 0.668 & 0.667 & 0.668 \\
\hline$\gamma_{7}$ & 0.011 & 0.023 & 0.011 & 0.011 & 0.011 & 0.011 \\
\hline$\gamma_{8}$ & 0.038 & 0.075 & 0.038 & 0.037 & 0.038 & 0.038 \\
\hline$\gamma_{9}$ & 0.228 & 0.457 & 0.231 & 0.230 & 0.232 & 0.230 \\
\hline \multicolumn{7}{|l|}{ Public } \\
\hline$\gamma_{3}$ & 0.051 & 0.103 & 0.052 & 0.052 & 0.052 & 0.052 \\
\hline$\gamma_{4}$ & 0.488 & 0.343 & 0.480 & 0.484 & 0.467 & 0.486 \\
\hline$\gamma_{7}$ & 0.011 & 0.023 & 0.011 & 0.011 & 0.011 & 0.011 \\
\hline$\gamma_{8}$ & 0.038 & 0.075 & 0.038 & 0.038 & 0.037 & 0.038 \\
\hline$\gamma_{9}$ & 0.411 & 0.457 & 0.419 & 0.415 & 0.433 & 0.413 \\
\hline
\end{tabular}

Source: Authors 
Table 6 Overview of CAADP policy programs

\begin{tabular}{l}
\hline Pillar I: Agricultural markets \\
\hline$\gamma_{1}:$ Subsidy payment to maize \\
\hline$\gamma_{2}:$ Subsidy payment to all agricultural production \\
\hline Pillar II: Infrastructure \\
\hline$\gamma_{3}:$ Improvement of infrastructure for agricultural exports \\
\hline$\gamma_{4}:$ General infrastructure improvement \\
\hline Pillar III: Land and water policy \\
\hline$\gamma_{5}:$ Land policy \\
\hline$\gamma_{6}:$ Water policy \\
\hline Pillar IV: Supporting institutional environment of the agricul- \\
tural sector \\
\hline$\gamma_{7}:$ Support of research and development facilities \\
\hline$\gamma_{8}:$ Support of extension services \\
\hline Other: Non-agricultural policy \\
\hline$\gamma_{9}:$ Non-agricultural policy
\end{tabular}

Source: Authors

\section{References}

Badiane, O., S. P. Odjo, and F. Wouterse. 2011. Comparative analysis of strategies and long term outlook for growth and poverty reduction among ECOWAS member countries. Discussion paper. Dakar: West and Central Africa Office.

Benin, S., S. Fan, and M. Johnson. 2012. Estimating public agricultural expenditure requirements. In Strategies and priorities for African agriculture: Economywide perspective from country studies, ed. X. Diao, J. Thurlow, S. Benin, and S. Fan. Washington, DC: International Food Policy Research Institute.

Brzeska, J., X. Diao, S. Fan, and J. Thurlow, eds. 2012. African agriculture and development. In Strategies and priorities for African agriculture: Economywide perspective from country studies. Washington, DC: International Food Policy Research Institute.

Diao, X., P. Hazel, D. Resnick, and J. Thurlow. 2007. The role of agriculture in development: Implications for sub-Saharan Africa. IFPRI Discussion Paper 153. Washington, DC: International Food Policy Research Institute (IFPRI).

Diao, X., J. Thurlow, S. Benin, and S. Fan, eds. 2012. Strategies and priorities for African agriculture: Economywide perspective from country studies. Washington, DC: International Food Policy Research Institute.

Duke, R.D. 1974. Gaming, the future's language. Beverly Hills, CA: Sage.

Durning, D. 1993. Participatory policy analysis in a social service agency: A case study. Journal of Policy Analysis and Management 12 (2): 297.

Fan, S., and M. W. Rosegrant. 2008. Investing in agriculture to overcome the world food crisis and reduce poverty and hunger. IFPRI Policy Briefs 3 . Washington, DC: International Food Policy Research Institute (IFPRI). 
Fan, S., and X. Zhang. 2004. Investment, reforms and poverty in rural China. Economic Development and Cultural Change 52 (2): 395-422.

Geurts, J.L.A., and C. Joldersma. 2001. Methodology for participatory policy analysis. European Journal of Operational Research 128 (2): 300-310.

Heckelei, T., R. Mittelhammer, and T. Jansson. 2008. A Bayesian alternative to generalized cross entropy solutions for underdetermined econometric models (Discussion Paper 2). Bonn: Institute for Food and Resource Economics, University of Bonn.

Henning, C.H.C.A. 2009. Networks of power in the CAP system of the EU-15 and EU-27. Journal of Public Policy 29 (02): 153-177.

Joldersma, C. 1997. Participatory policy making: Balancing between divergence and convergence. European Journal of Work and Organizational Psychology 6 (2): 207-218.

Knoke, D., F.U. Pappi, J. Broadbent, and Y. Tsujinaka. 1996. Comparing policy networks. Labor politics in the U.S., Germany, and Japan. Cambridge: Cambridge University Press.

Laumann, E.O., and D. Knoke. 1987. The organizational state: Social choice in national policy domains. Wisconsin: University of Wisconsin Press.

Pappi, F.U., and C.H.C.A. Henning. 1999. The organization of influence on EC's common agricultural policy: A network approach. European Journal of Political Research 36 (2): 257-281.

Pappi, F.U., T. König, and D. Knoke. 1995. Entscheidungsprozesse in der Arbeits- und Sozialpolitik. Frankfurt: Main.

Persson, T., and G. Tabellini. 2000. Political economics - Explaning economic policy. Cambridge: MIT Press.

Snijders, T.A. 2002. Markov chain Monte Carlo estimation of exponential random graph models. Journal of Social Structure 3 (2): 1-40.

Christian Henning is professor and chair of agricultural economics, University of Kiel (Germany). He studied economics, agricultural economics, sociology, political science and mathematics. He earned a PhD in economics, in agricultural economics and in political science. His main areas of specialization are applied political economy and applied economic modelling of agricultural policies. To date he has published five books and various articles in refereed journals including PLoS ONE, American Journal of Agricultural Economics, European Review of Agricultural Economics, Journal of Public Policy, Journal of Mathematical Sociology and Journal of Theoretical Politics.

Johannes Hedtrich is a computer scientist and a phd student in agricultural economics.He studied computer science and agricultural economics at the University of Kiel (Germany). His main areas of specialization are computational economics, Bayesian econometrics and social network analysis.

Ligane Massamba Sène is a Research Economist at the African Union. He holds a $\mathrm{PhD}$ in Agricultural Economics from the University of Kiel and a MSc Degree-Engineer in Statistics and Economics from ENSAE. He also studied Mathematics, Physics and Computer Science. His research interests include macroeconomic, macrosectoral and economic modeling of development and agricultural policies-Poverty, Inclusive growth and optimizing public expenditures-Taxation, social policies and household welfare-Modeling and Econometrics. 
Eva Krampe is an agricultural sector expert at the European Investment Bank. She studied agricultural economics and earned a PhD in agricultural economics at the University of Kiel. Her main areas of specialization are Africa's Agricultural Policy, Applied Political Economy and Economic Analysis of Agricultural Investment Projects.

Open Access This chapter is licensed under the terms of the Creative Commons Attribution 4.0 International License (http://creativecommons.org/licenses/by/4.0/), which permits use, sharing, adaptation, distribution and reproduction in any medium or format, as long as you give appropriate credit to the original author(s) and the source, provide a link to the Creative Commons license and indicate if changes were made.

The images or other third party material in this chapter are included in the chapter's Creative Commons license, unless indicated otherwise in a credit line to the material. If material is not included in the chapter's Creative Commons license and your intended use is not permitted by statutory regulation or exceeds the permitted use, you will need to obtain permission directly from the copyright holder.

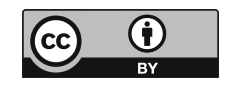

